\title{
«Лахта Центр»: автоматизированный мониторинг деформаций несущих конструкций и основания
}

\author{
В.И.Травуш, ГОРПРОЕКТ, Москва
}

\author{
А.М.Шахраманьян, СОДИС ЛАБ, Москва \\ Ю.А.Колотовичев, СОДИС ЛАБ, Москва \\ А.И.ШаХворостов, ИНФОРСПРОЕКТ, МосКва \\ М.А.Десяткин, ИНФОРСПРОЕКТ, Москва \\ 0.А.Шулятьев, НИИОСП им. Н.М. Герсеванова, Москва \\ С.О.Шулятьев, НИИОСП им. Н.М. Герсеванова, Москва
}

Многофункциональный комплекс МФК «Лахта Центр» - масштабный проект общественно-деловой застройки Приморского района Санкт-Петербурга. В состав комплекса вошли три уникальных сооружения: сверхвысокая Башня, большепролётные Многофункциональное здание (МФЗ) и входная Арка ${ }^{1}$, объединённые общей стилобатной частью. При возведении объектов комплекса было задействовано множество инновационных строительных технологий, применены нестандартные проектные решения.

В соответствии с действующими нормативными документами для обеспечения безопасности возведения и эксплуатации уникальных зданий в рамках проведения научно-технического сопровождения (НТC) строительства был организован комплекс мероприятий по постоянному мониторингу напряжённо-деформированного состояния (НДС) конструкций МФК.

Основная цель проведения мониторинга - минимизировать вероятность возникновения аварийных ситуаций, вызванных неопределённостями в работе несущих конструкций здания и грунтов основания.

В статье приводится общая информация о проектных и организационных решениях по внедрению системы автоматизированного мониторинга НДС конструкций Башни МФК «Лахта Центр». Даны подробные сведения об архитектуре и топологии системы, описаны применяемое оборудование, методика проведения измерений, программное обеспечение и регистрируемые с его помощью параметры напряжённодеформированного состояния сооружений

0бобщён опыт проектирования, монтажа, наладки и эксплуатации системы мониторинга деформаций несущих конструкций Башни во время её возведения. Особое внимание уделено результатам сопоставления расчётов ряда ответственных конструкций с данными инструментального мониторинга. Отмечены проблемы, неизбежно возникающие при интерпретации результатов мониторинга, предложены пути их решения.

Особо подчёркнута ценность данных, предоставляемых системами автоматизированного мониторинга, для повышения качества научно-технического сопровождения строительства

${ }^{1}$ В статье приняты проектные написания названия МФК и составляющих его объектов. и калибровки компьютерных моделей основания, фундамента и несущих конструкций зданий.

Ключевые слова: «Лахта Центр», СМДС, СМИК, система мониторинга конструкций, геотехнический мониторинг, программное обеспечение, мониторинг основания, высотное здание.

Lakhta Center: Automated Structural and Geotechnical Health Monitoring

V.I.Travush, GORPROJECT, Moscow

A.M.Shakhramanyan, SODIS LAB, Moscow.

Y.A.Kolotovichev, SODIS LAB, Moscow

A.I.Shakhvorostov, INFORCEPROJECT, Moscow

M.A.Desyatkin, INFORCEPROJECT, Moscow

0.A.Shulyatyev, NIIOSP named after N.M. Gersevanov, Moscow

S.0.Shulyatyev, NIIOSP named after N.M. Gersevanov, Moscow

"Lakhta Center" became a large scale public and office project in Primorskiy district of Saint-Petersburg, Russia. The Complex is comprised of supertall Tower, Multifunctional Building and the Arch with long span structures integrated with stylobate part. A number of innovation technologies and design solutions have been applied during the construction of the project.

According to the Building Codes and Regulations, to improve structural safety during the construction and maintenance periods, permanent structural health monitoring (SHM) program has been developed.

The main objective of SHM is to minimize structural failure risks due to uncertainties in soil and structural materials behavior.

General information about design and organizational arrangements for deploying automated structural and geotechnical health monitoring system of the "Lakhta Tower" is provided in the following paper. SHM architecture and topology, applied instrumentation, measurement methodology, software and monitoring parameters of the structure are described.

The article presents the results of the Tower structural behavior monitoring during the construction period. The correlation between the measured and the predicted Tower structure performance was analyzed and found in good agreement. A few anomalies were identified and investigated. 
The focus is made to the informational value of the monitoring data for the increasing of soil, foundation and structure FE-modelling quality for construction accompaniment purposes.

Keywords: "Lakhta-Center", structural health monitoring, geotechnical monitoring, SHM software, structural performance, monitoring program, high-rise building.

Многофункциональный общественно-деловой комплекс (МФК) «Лахта Центр», возводимый на берегу Финского залива в черте Санкт-Петербурга, стал самым высоким небоскрёбом в Европе. Высота Башни, входящей в состав комплекса, составляет 462 метра.

Для наблюдения за уникальными зданиями МФК была спроектирована автоматизированная система мониторинга деформационного состояния (СМДС), объединившая системы геотехнического мониторинга, деформаций коробчатого фундамента (КФ), мониторинга НДС высотной части Башни, мониторинга конструкций «Многофункционального Здания» (МФЗ) и входной Арки.

Разработка программы (рис. 1) мониторинга фундаментов и надземной части Башни была выполнена специалистами «SAMSUNG C\&Т», «ГОРПРОЕКТ», «СОДИС ЛАБ», «ИНФОРСПРОЕКТ» и НИИОСП им. Н.М. Герсеванова в 2015 году.
С 2013 года был установлен режим периодического ручного геотехнического мониторинга основания. В 2015 году с началом возведения фундаментных конструкций начались работы по периодическому мониторингу деформаций КФ, которые продолжались вплоть до запуска в мае 2016 года автоматической системы сбора данных, позволившей осуществлять автоматизированную передачу данных мониторинга в штаб строительства. Впоследствии, по мере возведения конструкций Башни, к автоматической системе подключалось новое измерительное оборудование. После завершения всего комплекса пуско-наладочных работ система мониторинга будет интегрирована с системой управления зданием (BMS) и пополнится рядом измерительных систем (рис. 2), которые будут способствовать безопасной эксплуатации уникальных зданий МФК.

\section{Краткие сведения об объекте мониторинга}

Башня «Лахта Центра» имеет три подземных и 86 надземных этажей. Форма здания закрученная конусообразная. Плиты перекрытий выполнены в форме пяти квадратных «лепестков», соединённых между собой круглым центральным ядром. По мере увеличения высотной отметки квадратные «лепестки» поворачиваются вокруг своей оси против часовой стрелки, а их площадь уменьшается.

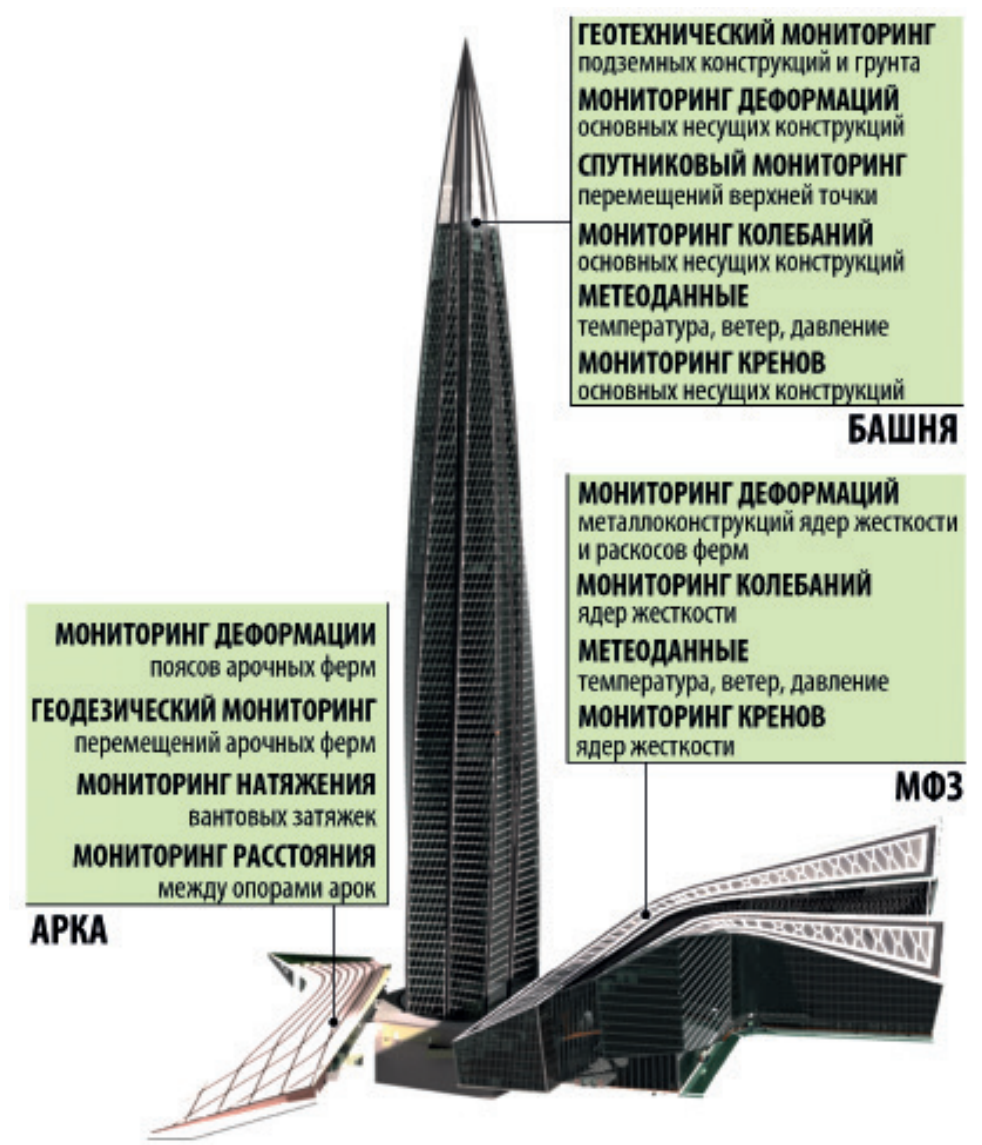

Рис. 1. Система автоматизированного мониторинга МФК «Лахта Центр»

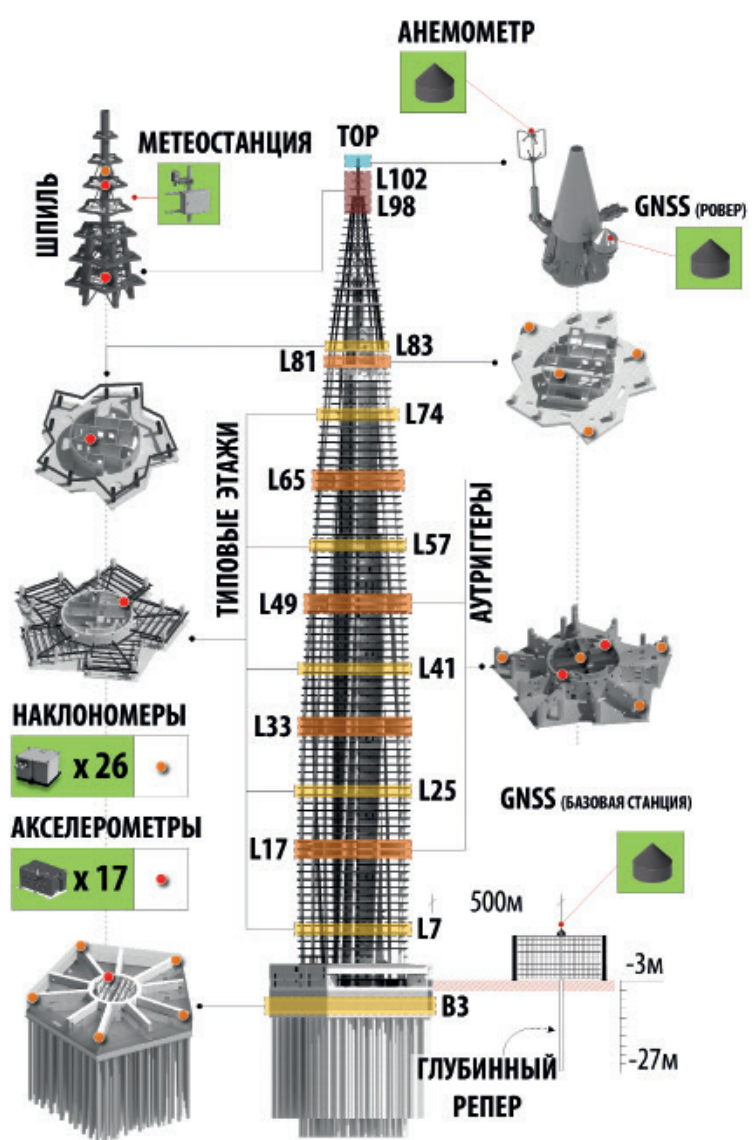

Рис. 2. Состав системы мониторинга надземной части Башни 
Проект Башни потребовал от его разработчиков решения большого количества сложных инженерных задач. Одной из них было проектирование конструкций фундамента в условиях опирания на глинистые грунты низкой несущей способности. Нагрузку от высотного здания было решено передавать с помощью свай на твёрдые вендские глины (ИГЭ-7...9 на рис. 3), залегающие на глубине около 20 метров с модулем деформации, увеличивающимся с глубиной от 28 МПа до 340 МПа (правая часть рис. 3), особенностью которых является наличие реологических свойств, способных увеличить конечную осадку сооружения до 25\%.

В соответствии с проектными решениями, наиболее нагруженной частью сооружения является центральное ядро, через которое передается до 70\% нагрузки от сооружения. Для компенсации неравномерной нагрузки на основание было принято решение об устройстве 264 буронабивных свай диаметром 2 м с длинами 55 м и 65 м. Более длинные сваи расположили под центральным ядром для создания дополнительной жёсткости [1] (рис. 4).

Значительная часть веса здания приходится на небольшой участок диаметром 26 метров, ограниченный круглым центральным ядром. Непосредственная передача этой нагрузки на грунт создавала бы давление до 6,5 МПа. Для увеличения площади передачи нагрузки на основание и сохранения приемлемой разности осадок был спроектирован коробчатый фундамент (КФ) высотой 16,6 м, состоящий из двух плит толщиной 3,6 м (нижняя), 2,0 м (верхняя) и 10 диафрагм толщиной 2,5 м. При изготовлении КФ был применён высокопрочный бетон класса В60.

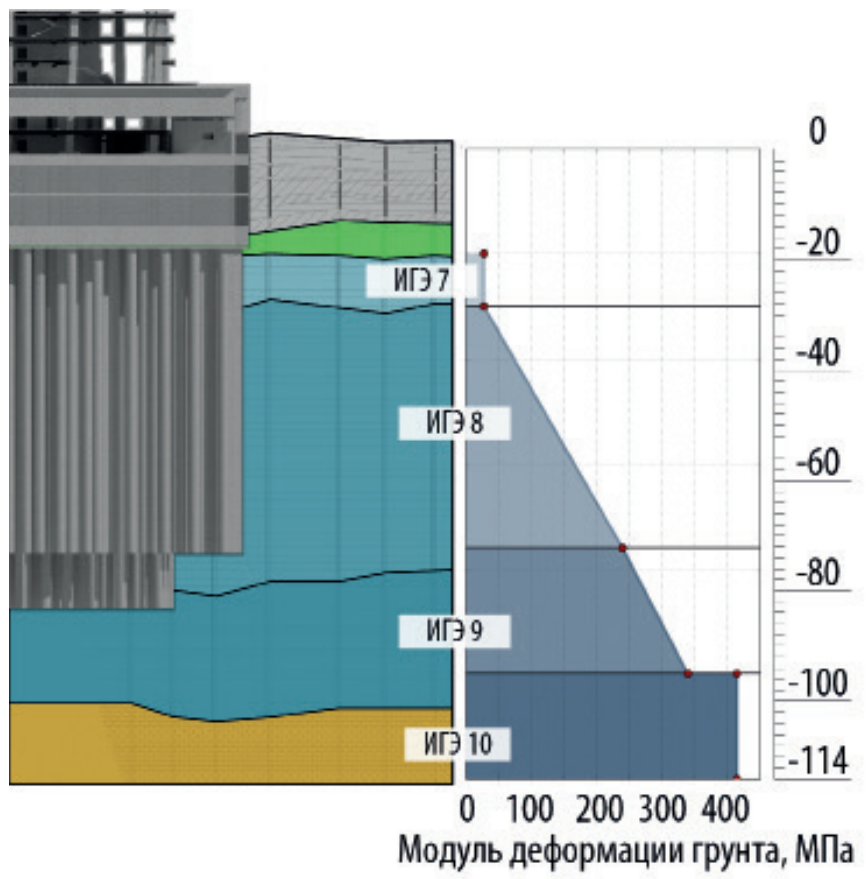

Рис. 3.Инженерно-геологические условия площадки строительства

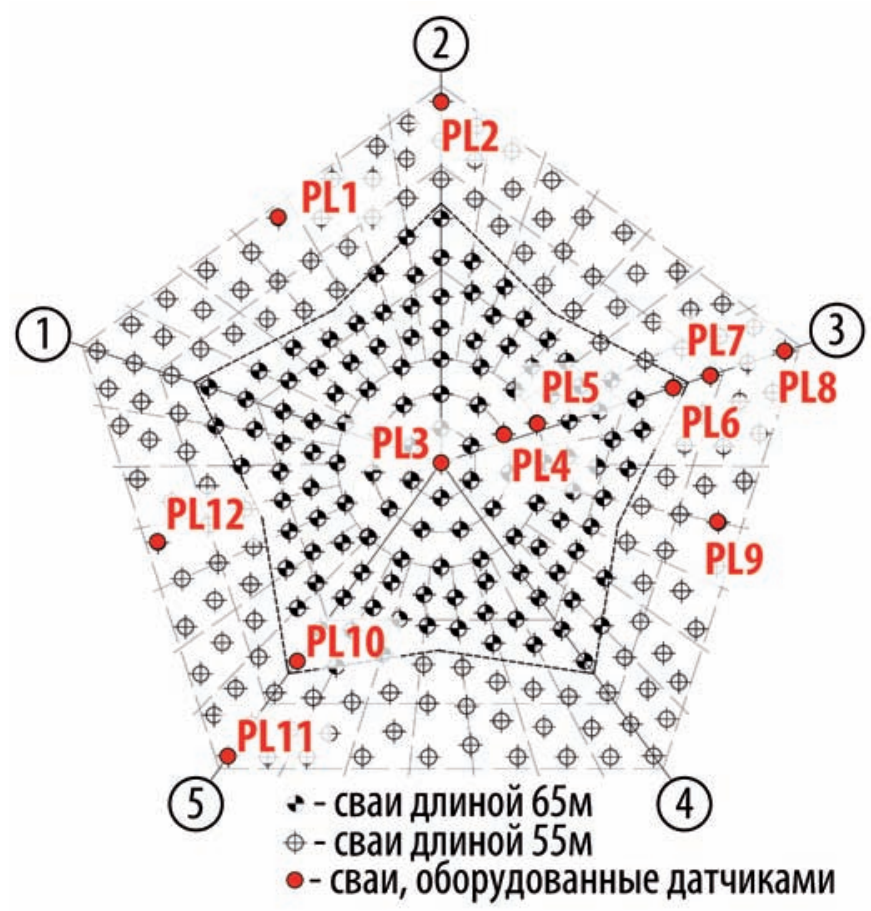

Рис. 4. Схема расположения свай

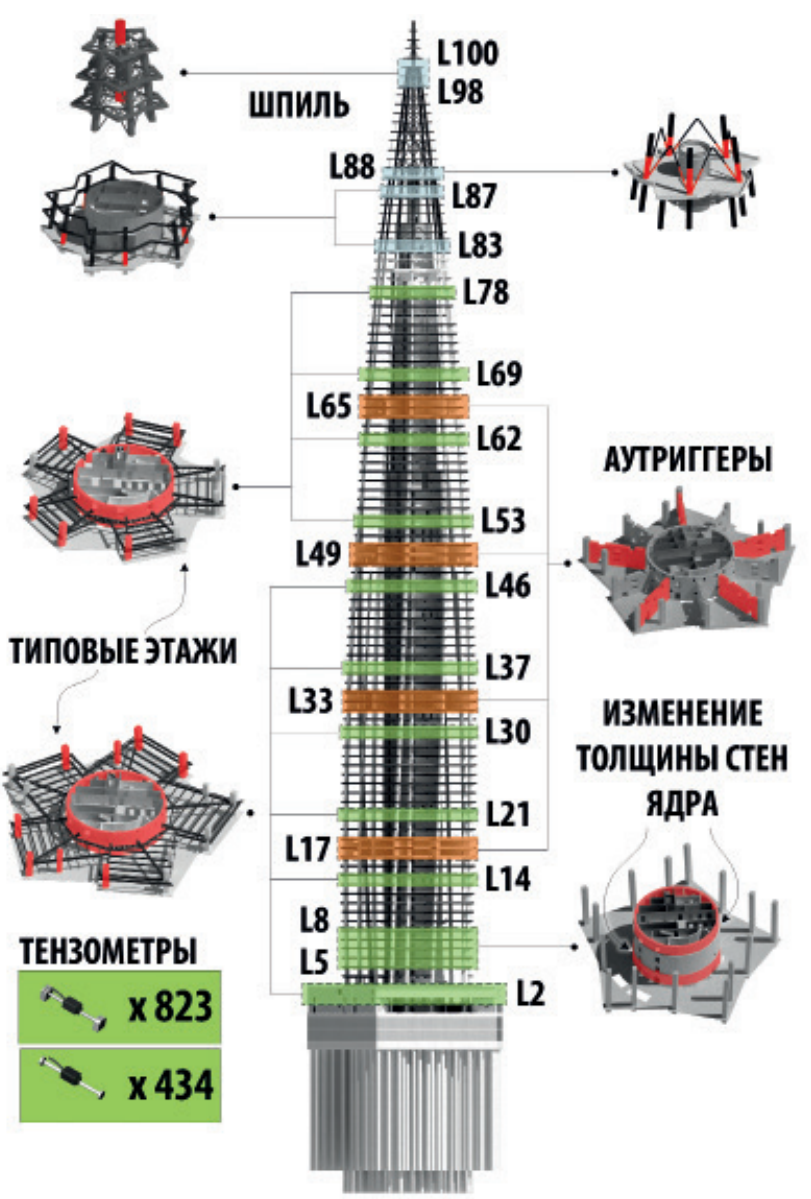

Pис. 5. Система мониторинга деформации конструкций надземной части Башни 
Конструктивная схема здания - каркасно-ствольная. Основные несущие конструкции - центральное железобетонное ядро и десять сталежелезобетонных колонн по периметру, соединённых с ядром аутриггерными этажами, повышающими жёсткость здания и его устойчивость к прогрессирующему обрушению. Аутриггеры запроектированы в виде железобетонных балок-стен с инсталлированными в тело железобетона стальными фермами. В вертикальных конструкциях надземной части применён бетон класса В80.

Сталежелезобетонные колонны состоят из металлического сердечника и железобетонной части, дополнительно армированной гибкой стальной арматурой.

Стальной шпиль башни выполнен в виде пятигранной пирамиды, расположенной вокруг центрального ядра и опирающейся на перекрытие 83-го этажа (L83) на отметке +344,400 в местах расположения композитных колонн. Высота шпиля - около 118 м, ширина грани у основания пирамиды шпиля - около 16 м.

Основные расчёты строительных конструкций Башни выполнены в программном комплексе «ЛИРА-САПР», геотехническая часть моделировалась в ПК «PLAXIS 3D». Проверочные расчёты выполнялись в ПК «SOFiSTiK». Наряду с гравитационными при расчёте здания определяющими были ветровые нагрузки, для изучения которых проводилось исследование масштабной модели в аэродинамической трубе.

Строительство небоскрёба было начато в октябре 2012 года с изготовления опытных свай и ограждающей конструкции котлована. При строительстве надземной части Башни активно использовались передовые технологии возведения. Бетонирование центрального ядра шло с опережением воз- ведения периметральных конструкций в среднем на 40-60 метров. Монтаж шпиля был завершён в начале 2018 года.

\section{Мониторинг надземной части Башни}

Надземная часть Башни оборудована автоматизированной системой мониторинга относительных деформаций, состоящей из 1257 струнных тензометров различного типа. С их помощью производятся измерения осевых деформаций композитных колонн на типовых этажах, вертикальных и горизонтальных деформаций стен железобетонного ядра, комплексный мониторинг деформации аутриггерных ферм и металлоконструкций шпиля (рис. 5). Система вводится в эксплуатацию поэтапно (рис. 6) в процессе возведения несущего каркаса.

Выше (см. рис. 2) приведена схема расположения измерительного оборудования, установленного в надземной части здания в дополнение к системе мониторинга деформаций.

Контроль крена Башни в двух плоскостях, необходимый в том числе для нормальной эксплуатации лифтового оборудования и фасадных систем, производится с помощью 26 высокоточных наклономеров «Leica Nivel 220», установленных на аутриггерных этажах и конструкциях шпиля.

Анализ динамического отклика здания (определения частот, форм собственных колебаний, модальных декрементов затухания), вызываемого ветровой нагрузкой, работой технологического оборудования и другими факторами выполняется с помощью 17 низкочастотных трёх- и двухкомпонентных форс-балансных акселерометров «Geosig AC-72 (73)», смонтированных по всей высоте Башни. Система предоставляет информацию о колебаниях здания, которая необходима для

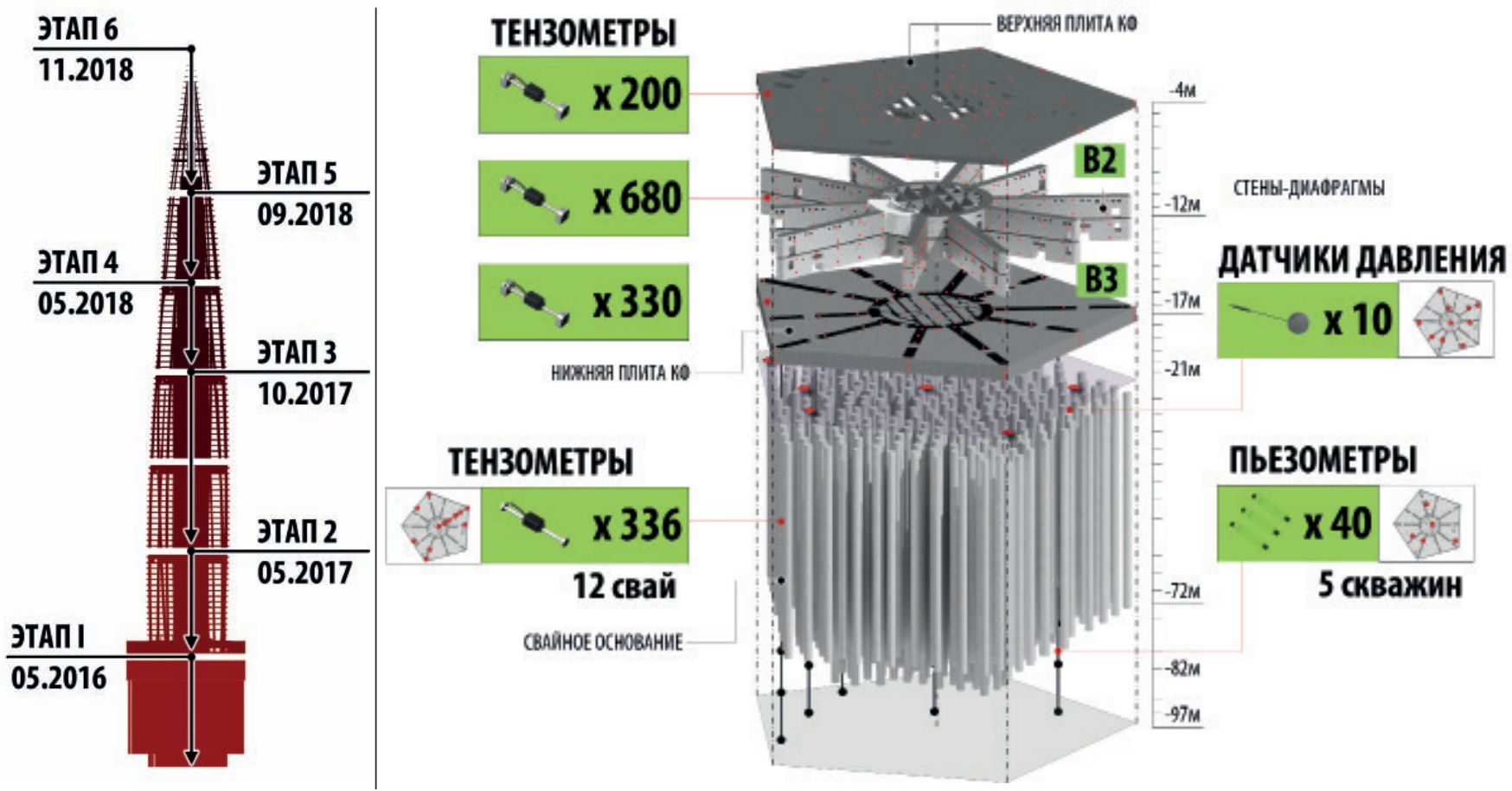

Puс. 6. Стадийность запуска автоматизированной системы мониторинга деформаций

Puс. 7. Автоматизированная система геотехнического мониторинга и мониторинга деформаций КФ 
интегральной оценки изменений с течением времени технического состояния конструкций и калибровки параметров расчётной модели.

Мониторинг планово-высотныхперемещений верхней точки здания в режиме реального времени и с постобработкой производится с помощью системы спутникового геодезического мониторинга. Антенна GNSS-приёмника «Novatel ProPak6» в наблюдаемой точке закреплена на навершии шпиля. Неподвижная точка, относительно которой производится измерение перемещений, установлена на глубинном репере, смонтированном на расстоянии около 500 метров от Башни. Связь с приёмниками производится с помощью волоконно-оптической линии. Спутниковый мониторинг перемещений верхней точки в совокупности с результатами мониторинга кренов и колебаний предоставляет исчерпывающую информацию о деформации оси здания.

Установка двух метеостанций (вторая смонтирована на кровле МФЗ и осуществляет измерение климатических параметров в приземной зоне) позволит производить корреляционный анализ параметров НДС и отделять изменения параметров, связанных с деградацией строительных конструкций, от сезонных и климатических изменений.

Введение перечисленных измерительных систем в эксплуатацию предполагается на завершающих этапах строительства.

\section{Система мониторинга деформации коробчатого}

фундамента

Система мониторинга деформации КФ (рис. 7) - наиболее масштабная и сложная подсистема в составе СМДС, - была спроектирована для анализа изменений НДС фундамента, который в 2015 году попал в Книгу рекордов Гиннеса как самая массивная конструкция из железобетона (19,6 тысяч куб.м), отлитая непрерывным способом.

Для контроля напряжённо-деформированного состояния на стержни рабочей арматуры нижней плиты, стен-диафрагм и верхней плиты было установлено в общей сложности 1210 струнных тензометров, объединённых в 196 створов (рис. 8).

Каждый створ, в зависимости от типа конструкции и характера её деформирования, включает в себя два или три измерительных пункта. Измерительные пункты оборудованы парой датчиков, ориентированных во взаимно перпендикулярных направлениях вдоль рабочих арматурных стержней. Такая конфигурация системы позволила с достаточной для сравнения с результатами расчёта точностью определить распределение напряжений по толщине плит и стен КФ.

\section{Система геотехнического мониторинга}

Программа геотехнического мониторинга была разработана сотрудниками 000 «НППП “СПЕЦГЕОПРОЕКТ”» при научно-техническом сопровождении НИИОСП им. Н.М. Герсеванова в 2013 году. Проектом было предусмотрено проведение мониторинга ограждающих конструкций (стены-в-грунте), несущих конструкций подземной части зданий Башни, МФЗ и стилобатной части, а также окружающего массива грунта, включая наблюдения за режимом подземных вод.

Монтаж измерительного оборудования для геотехнического мониторинга несущих конструкций Башни производился в 2013-2014 годах (см. рис. 7).

Для контроля действительного характера распределения нагрузки на свайное поле 12 из 264 свай были оборудованы закладными датчиками деформации струнного типа «Geokon 4200», установленными в семи уровнях. Для мониторинга распределения нагрузки между нижней плитой и сваями под бетонной подготовкой нижней плиты КФ разместили десять датчиков давления «Sisgeo L143».

Полученная информация позволяет в ходе НTC осуществлять корректировку параметров расчётных моделей грунта и фундаментных конструкций для точного прогнозирования осадок сооружения. Результаты прогноза позволяют своевременно организовать компенсирующие мероприятия для предотвращения последствий от неравномерных осадок фундамента.

Как указывалось ранее, длительные процессы консолидации в грунтах основания приведут к развитию осадок в ходе эксплуатации сооружения. Для оценки динамики осадок основание оборудовали пятью скважинами для мониторинга порового давления воды в грунте с восемью пьезометрами струнного типа «Sisgeo PK45М» в каждой. Пьезометры устанавливались методом полной цементации [2] скважин раствором на основе портландцемента и бентонита со средним шагом по глубине 10 м.
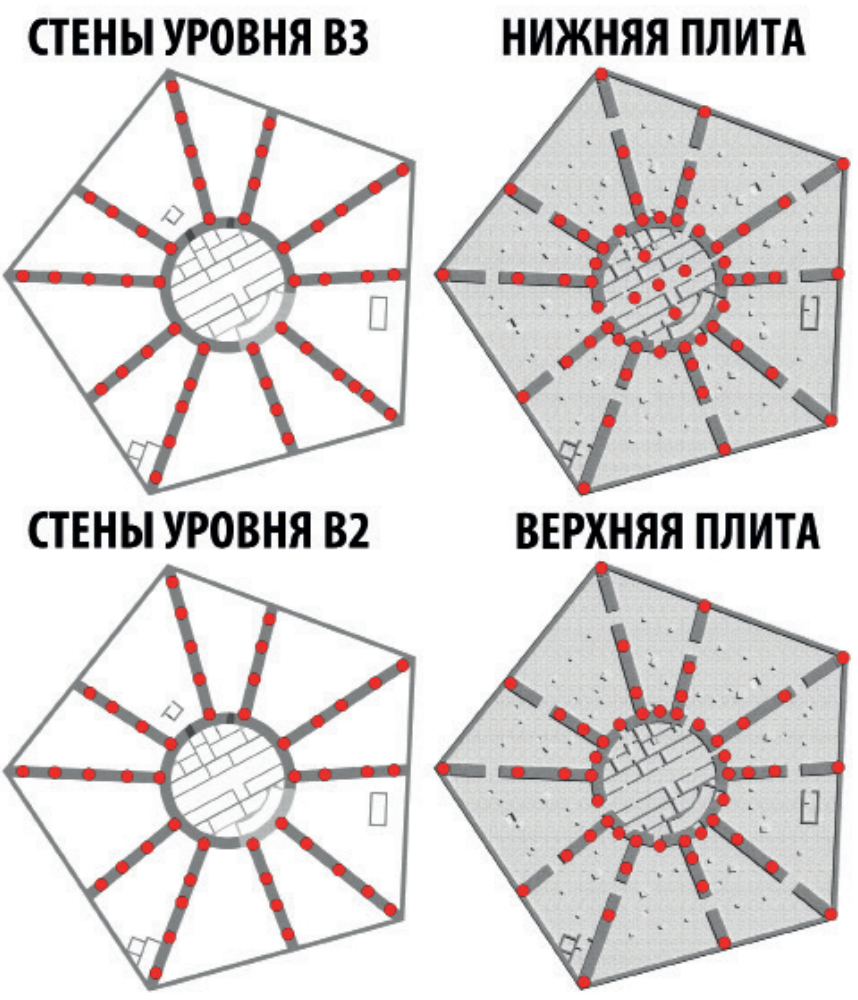

Рис. 8. Расположение створов с датчиками деформации в конструкциях КФ 
Проектные решения по организации автоматизированного мониторинга деформаций

Разработка архитектуры автоматизированной системы, проектной и рабочей документации и подбор оборудования были выполнены сотрудниками «СОДИС ЛАБ». Длительный срок эксплуатации системы (не менее десяти лет после окончания строительства) накладывает много ограничений на выбор датчиков. Стандартом для долговременного мониторинга медленно меняющихся деформаций в строительных конструкциях являются струнные тензометры, сохраняющие работоспособность на протяжении десятилетий [3; 4] и демонстрирующие отличную стабильность нуля [5].

Преимуществом струнной технологии над более распространёнными резистивными или полупроводниковыми датчиками является сам тип сигнала - частота собственных колебаний струны (а не напряжение, ток или сопротивление). Этот сигнал легко без искажений передать на большие расстояния, он не подвержен влиянию коррозии или попадания влаги на проводники кабельных линий, слабо чувствителен к наличию электромагнитных помех и не зависит от длины кабелей.

Установка тензометров в конструкции КФ и стены ядра осложнялась густым армированием (рис. 9). Монтаж датчиков осуществлялся на сетках рабочей арматуры с помощью приварки концевых блоков к арматурным стержням (рис. 10). Прокладка кабеля через горизонтальные конструкции выполнялась в раструбных ПВХ-трубах, которые наращивались

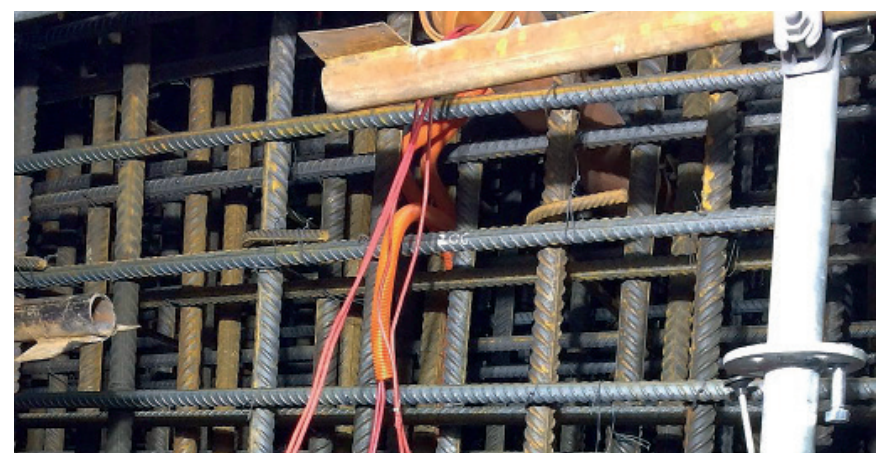

Рис. 9. Укладка кабелей тензодатчиков в закладные детали

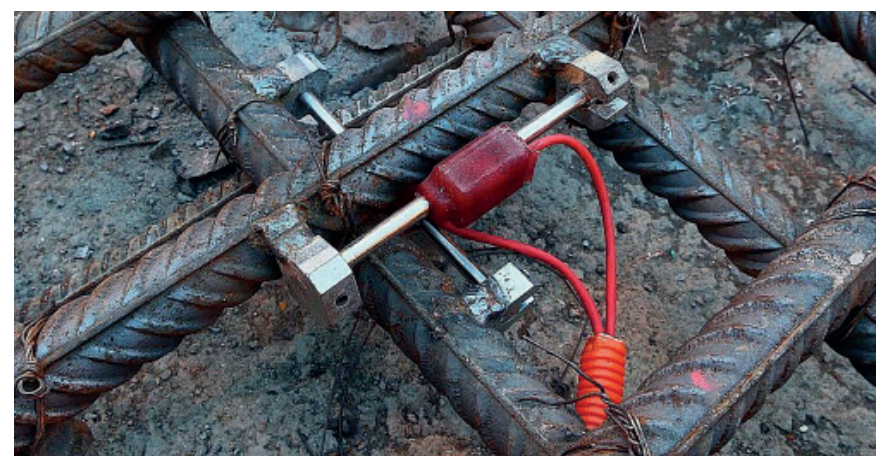

Pис. 10. Тензометры, смонтированные на арматуре нижней плиты КФ по мере устройства арматурного каркаса (рис. 11). Вывод кабелей из тела бетона осуществлялся исключительно на вертикальных конструкциях. На время бетонирования кабели сохранялись внутри специально подготовленных закладных деталей из ПВХ-изделий. После демонтажа опалубки закладные детали вскрывались, и кабели выводились наружу (рис. 12), где подключались к системе регистрации данных.

Одной из основных задач по организации автоматизированной системы мониторинга деформаций являлась необходимость её запуска на ранних стадиях строительства, что наложило ряд существенных ограничений на всю архитектуру системы. Было принято решение по развертыванию распределённой системы сбора данных в противовес централизованной. Оборудование для автоматической регистрации, размещаемое на технических этажах Башни (B3, B2, L18, L34, L50, L66, L81) по мере возведения несущих конструкций (рис. 13), образовало семь автономных подсистем, к которым подключили нижерасположенные датчики.

Хронологически развёртывание системы мониторинга деформаций разделилось на шесть этапов (см. рис. 6): на первом этапе запустили в эксплуатацию систему мониторинга деформаций КФ и оборудование системы геотехнического мониторинга, далее последовательно подключались типовые и аутриггерные этажи.

Все узлы сбора данных подключили к временной системе электропитания с аккумуляторным резервированием на случаи

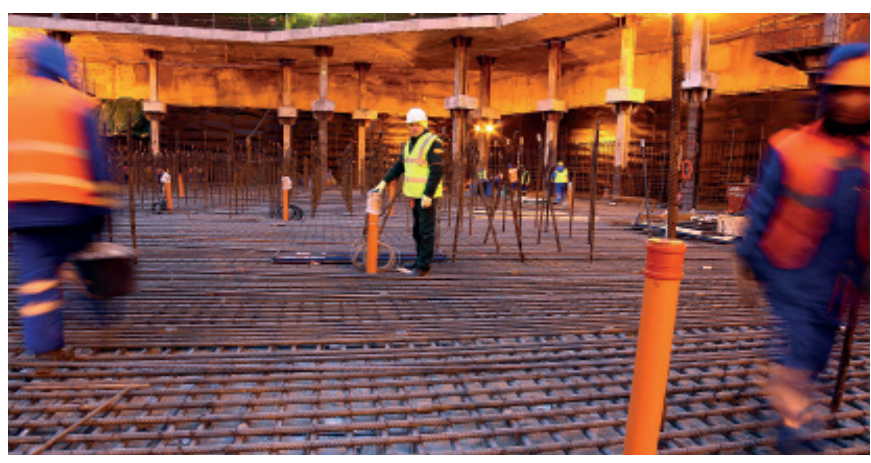

Рис. 11. Мероприятия по выводу кабелей из тела нижней плиты КФ
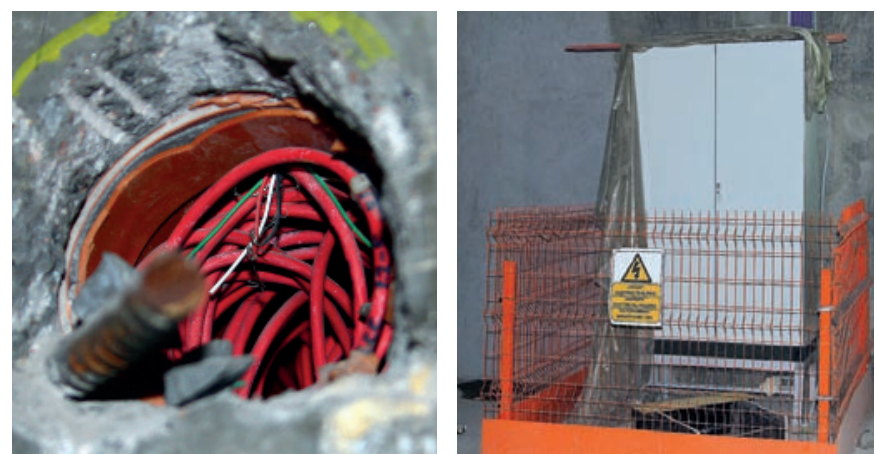

Рис. 12. Закладная деталь с Рис. 13. Размещение щитов кабелями тензометров, вскры- сбора данных в коробчатом тая после демонтажа опалуб- фундаменте ки стены КФ 
перебоев в электроснабжении. Связь между узлами обеспечили с помощью временной проводной сети передачи данных.

Несмотря на большие расстояния между узлами, от применения волоконнооптических линий связи отказались из-за сложности их ремонта в построечных условиях, остановившись на использовании «медных» технологий DSL и Ethernet.

Для уменьшения вероятности потери информации регистрация данных мониторинга осуществляется с помощью программируемых даталоггеров с внутренней памятью. Принципиальная архитектура системы изображена на рисунке 14.

Все узлы сбора данных были построены с использованием оборудования компании «Campbell Scientific» (рис. 15).

Для мониторинга конструкций КФ оборудовали два узла сбора данных на уровнях В3 и В2. Мультиплексорное оборудование установили непосредственно над закладными деталями в каждой точке выхода сигнальных кабелей из тела конструкций (рис. 16).

Такое решение позволило значительно сократить протяжённость кабельных линий, уменьшить вероятность повреждения кабелей в процессе строительства, упростить и удешевить ремонт, оперативно изменять трассировку кабелей и избавило от необходимости наращивать сигнальные кабели тензодатчиков.

Прокладка кабелей производилась в лотках (рис. 17), что свело случаи повреждения линий при строительных работах к единичным.

На аутриггерных этажах мультиплексоры установили в непосредственной близости от даталоггеров - в общих шкафах сбора данных. Это привело к необходимости устройства дополнительных коммутационных узлов для соединения магистральных кабелей с тензодатчиками, но уменьшило общее количество необходимого оборудования.

Универсальность струнного интерфейса позволила легко интегрировать оборудование для геотехнических задач в состав системы мониторинга деформаций.

Доставка данных мониторинга в штаб строительства (рис. $18,19)$ была организована с помощью беспроводного Wi-Fi моста.

Установка GPRS-модема обеспечила удалённую связь с сетью мониторинга через Интернет с помощью защищённого VPN-тоннеля (см. рис. 18). Это решение позволило оперативно предоставлять информацию, проводить техническое обслуживание и анализировать результаты мониторинга в онлайн-режиме.

\section{Программное обеспечение системы мониторинга}

Внедрение масштабной системы мониторинга, включающей в себя более 2800 датчиков, потребовало развёртывания и поддержки современной IT-инфраструктуры. В качестве программной платформы для работы с данными мониторинга было использовано окружение SODIS Building M4 (рис. 20), в состав которого входит большое число проблемно-ориентированных сервисов и инструментов для решения задач долговременного мониторинга строительных конструкций.

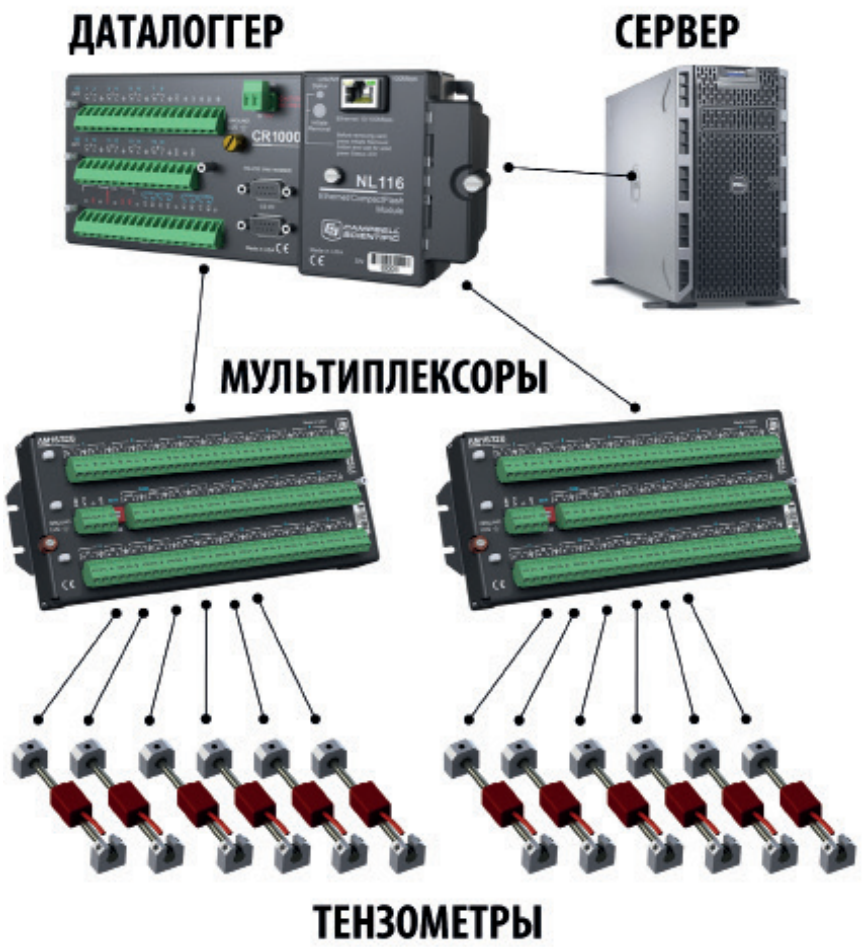

Рис. 14. Принципиальная архитектура автоматической системы сбора данных

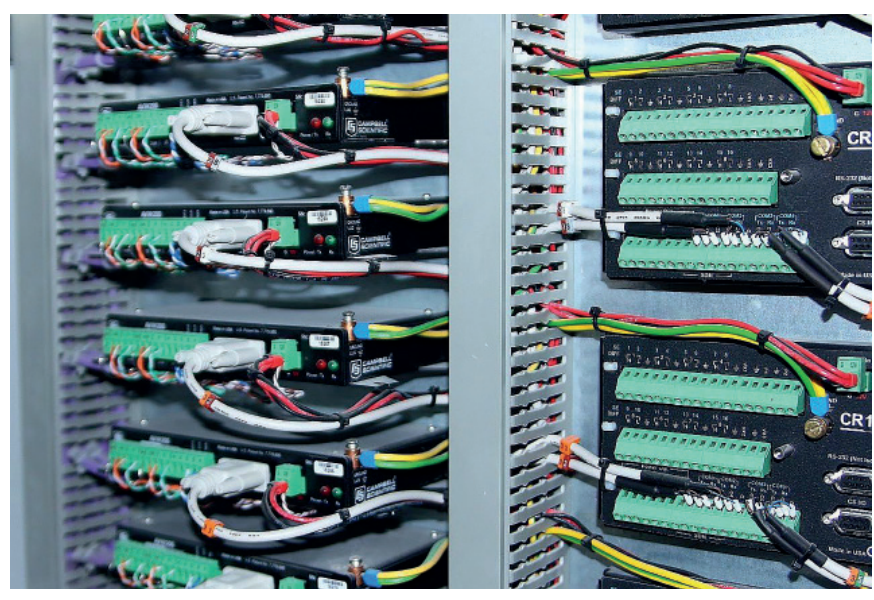

Puс. 15. Шкаф с даталоггерами системы сбора данных с датчиков КФ

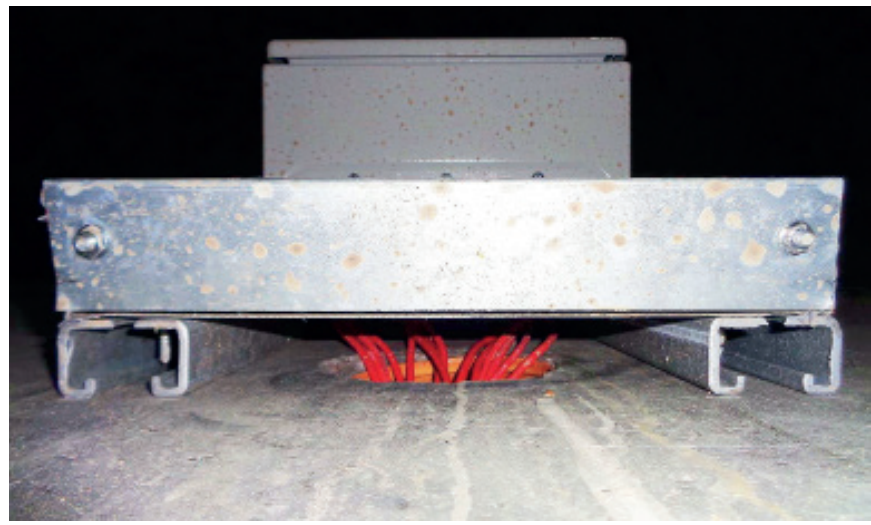

Рис. 16. Шкаф с мультиплексорами, установленный над закладной деталью на стене КФ 


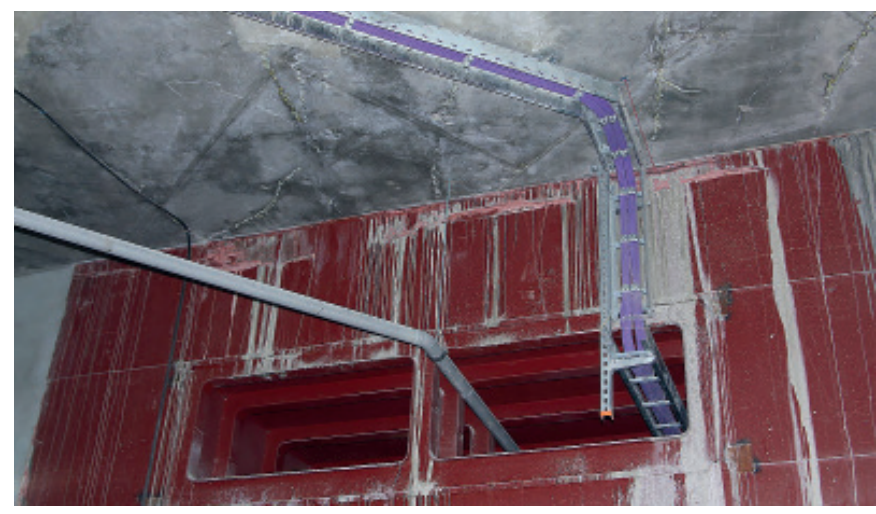

Рис. 17. Магистральные кабели от мультиплексоров к даталоггерам

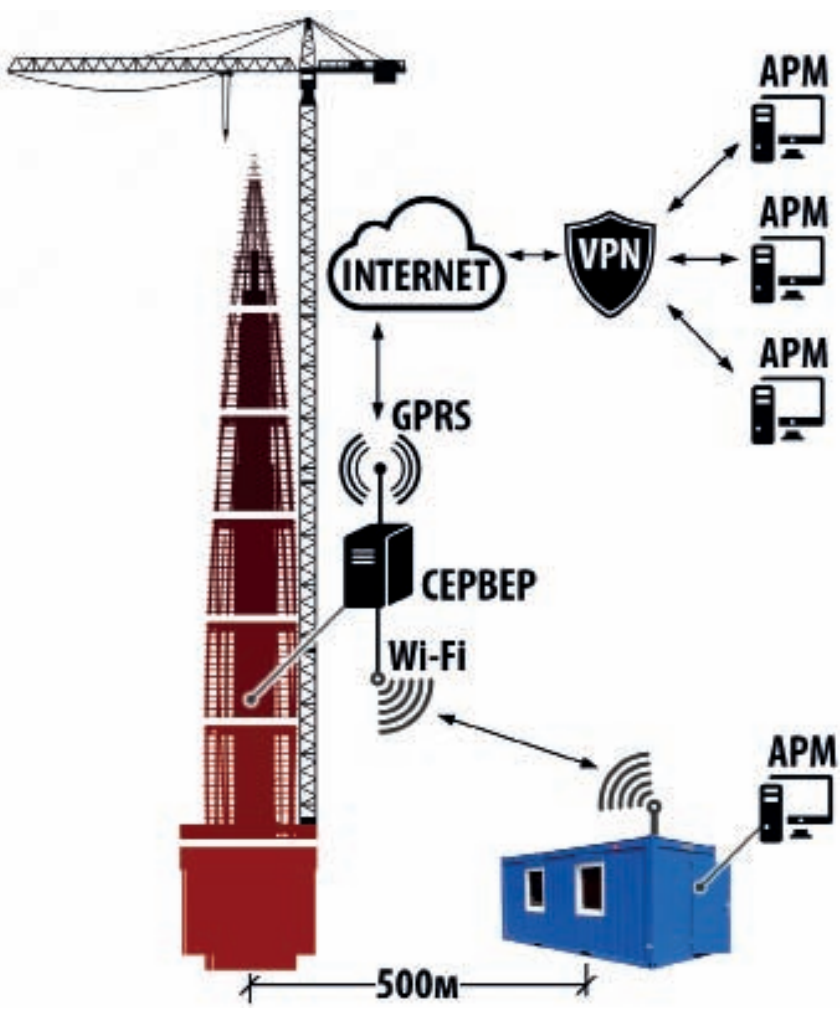

Puc. 18. Схема передачи данных мониторинга

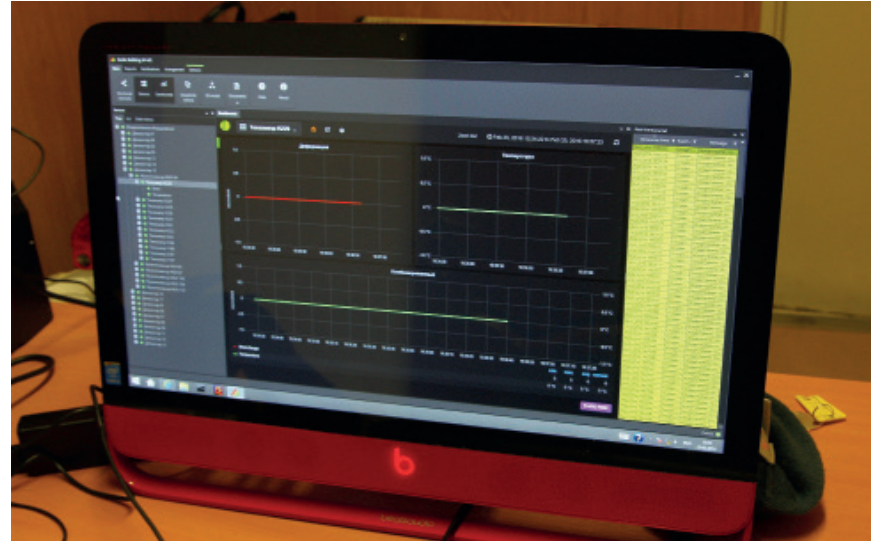

Рис. 19. Временный диспетчерский пункт в штабе Генподрядчика
Возможности программной платформы SODIS Building M (рис. 21) позволили обеспечить автоматизированный учёт индивидуальных характеристик датчиков (калибровочных коэффициентов, данных начальных замеров), метаинформации (координат мест установки, ориентации датчика, типа конструкции, деформационных характеристик материалов, геометрических характеристик сечений, принадлежности к измерительным створам и т.п.), необходимой для анализа данных, что позволило автоматическим способом перейти от непосредственных результатов измерений (деформации) к напряжениям и внутренним усилиям в элементах конструкций, для которых возможно произвести сравнение с расчётными величинами по результатам математического моделирования. Интерфейс разработки приложений (API) позволил автоматизировать обмен данными с ВIМ- и КЭмоделями Башни.

При выполнении пуско-наладочных работ были разработаны инструменты для автоматической генерации микропрограмм локальных контроллеров и автоматической обработки монтажных протоколов. К завершению работ по наладке первого пускового этапа были автоматизированы 95\% рабочих операций по настройке системы, что позволило исключить неизбежные ошибки исполнителей, вызванные выполнением рутинных операций, а также увеличить скорость наладки последующих блоков системы.

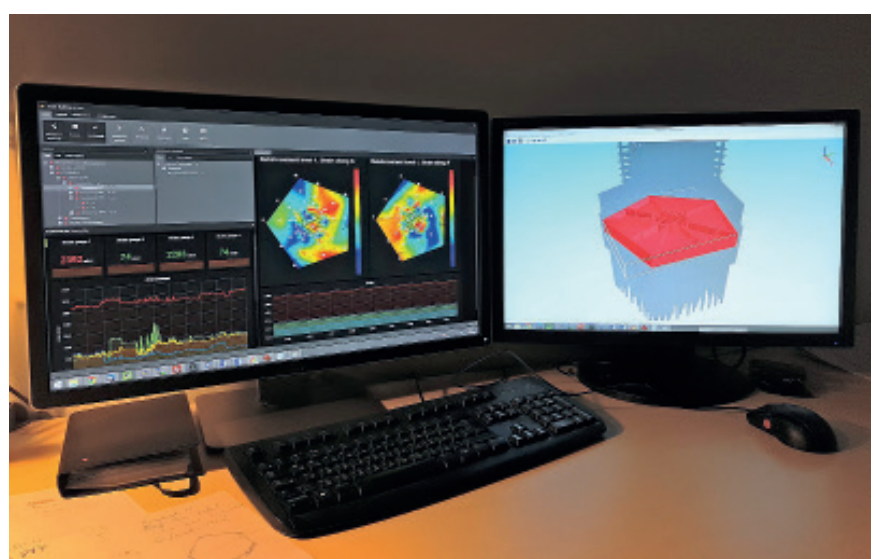

Puc. 20. Интерфейс ПК SODIS Building M

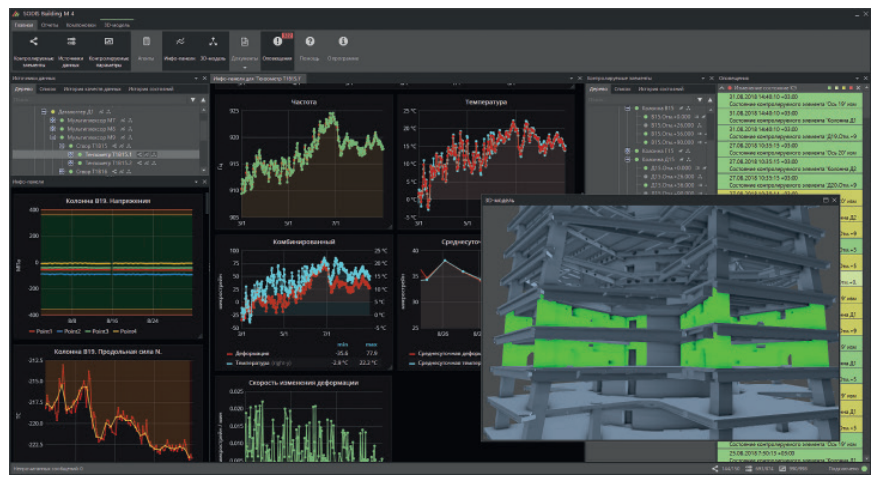

Puc. 21. Интерфейс ПК SODIS Building M 
Объём полученных данных мониторинга

По данным на конец августа 2018 года в базе данных системы мониторинга башни «Лахта Центра» находится почти 74 млн измерений, полученных от 2346 датчиков деформации, 9-ти датчиков давления и 39-ти пьезометров. Вся собранная информация была тщательным образом отфильтрована, очищена от случайных выбросов и нефизичных значений, дополнена результатами ручного мониторинга (рис. 22).

Полученные данные легли в основу расчётов компонент напряженно-деформированного состояния элементов конструкций Башни (рис. 23, 24).

Информация, полученная от геотехнического оборудования (датчиков давления и пьезометров), используется для уточнения жесткостных и консолидационных характеристик расчётной модели основания (рис. 25).

\section{Анализ результатов мониторинга}

Сопоставление данных мониторинга деформации с результатами конечно-элементного (КЭ) моделирования конструкций Башни - базовая задача НTC, решение которой позволяет приблизиться к определению действительного характера работы конструкций и определить слабые места в расчётной модели, оперативно отреагировать на опасные изменения НДС и не допустить развития аварийной ситуации. Для анализа результатов были взяты данные мониторинга по состоянию на 1 июля 2018 года. По нашим расчётам, на рассматриваемую дату несущие конструкции здания испытывали 100\% постоянных нагрузок, 100\% временных нагрузок на технические этажи, 100\% нагрузок от фасадных конструкций и 50\% нагрузок от полов, перегородок и коммуникаций.

В качестве одного из параметров, по которым выполнялось сравнение, выступили вертикальные усилия в композитных колоннах и стенах ядра в уровнях L2, L5, L8 и L14.

Расчет здания провели в трёх вариантах:

1) на действие временных нагрузок на техэтажах, собственный вес конструкций и фасадов, 50\% веса полов, перегородок и коммуникаций, на упругом основании;

2) на те же самые нагрузки, что и в предыдущем варианте, но с учётом последовательности возведения;

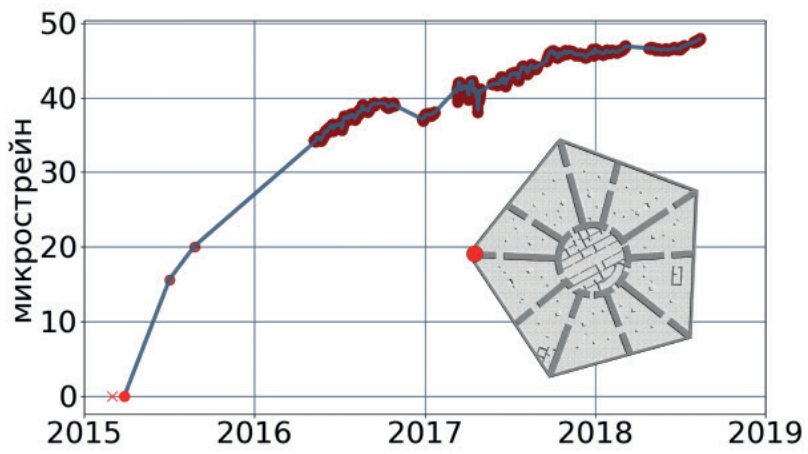

Pис. 22. Показания датчика деформации Х10 в нижней плите $\kappa \phi$

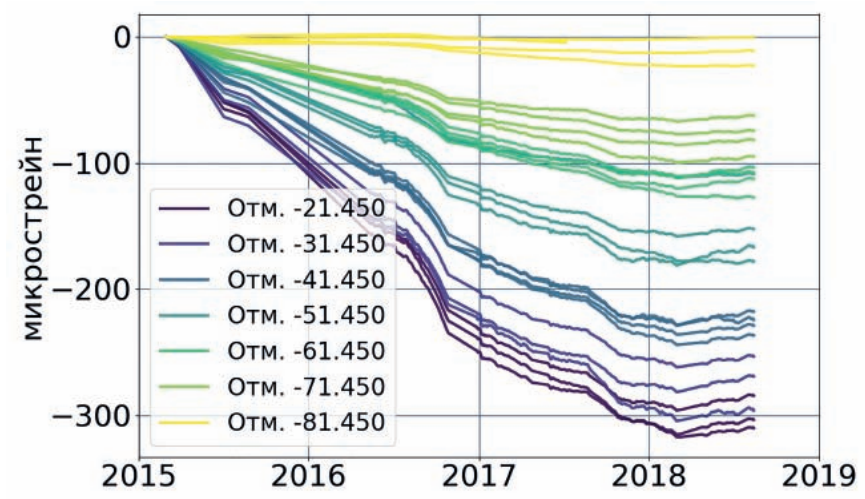

Рис. 23. Показания датчиков деформации в свае №4

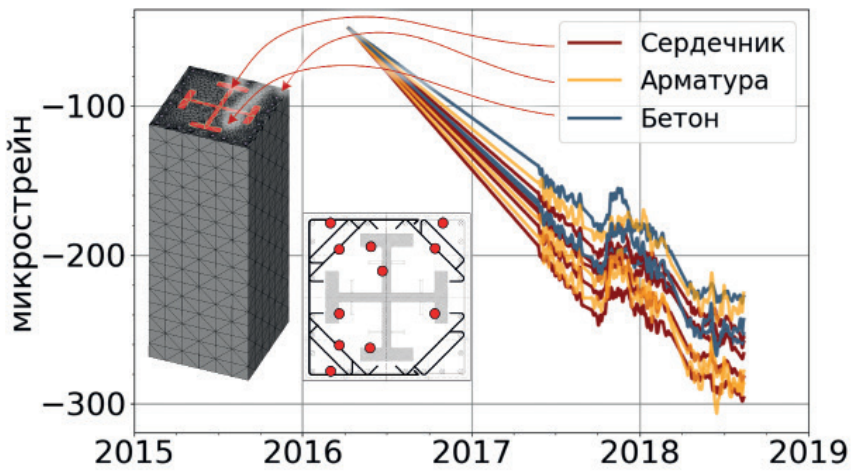

Рис. 24. Показания датчиков деформации в колонне №2 на уровне $L 14$

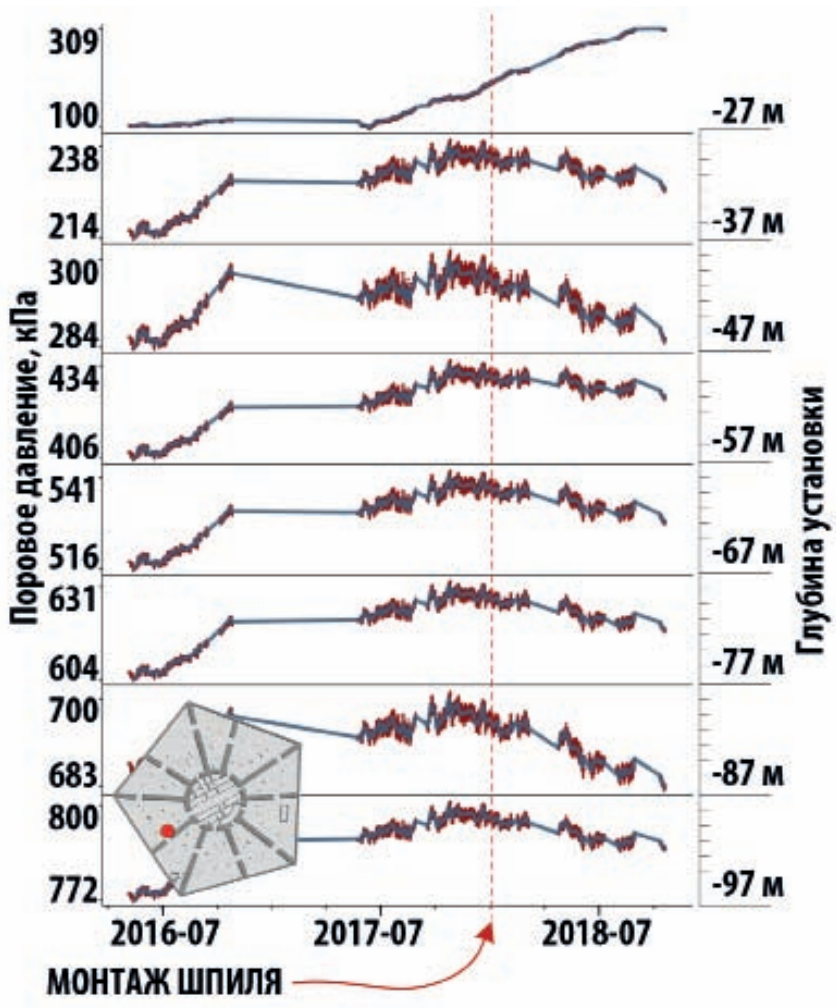

Рис. 25. Показания датчиков порового давления (пьезометров) в скважине №5 


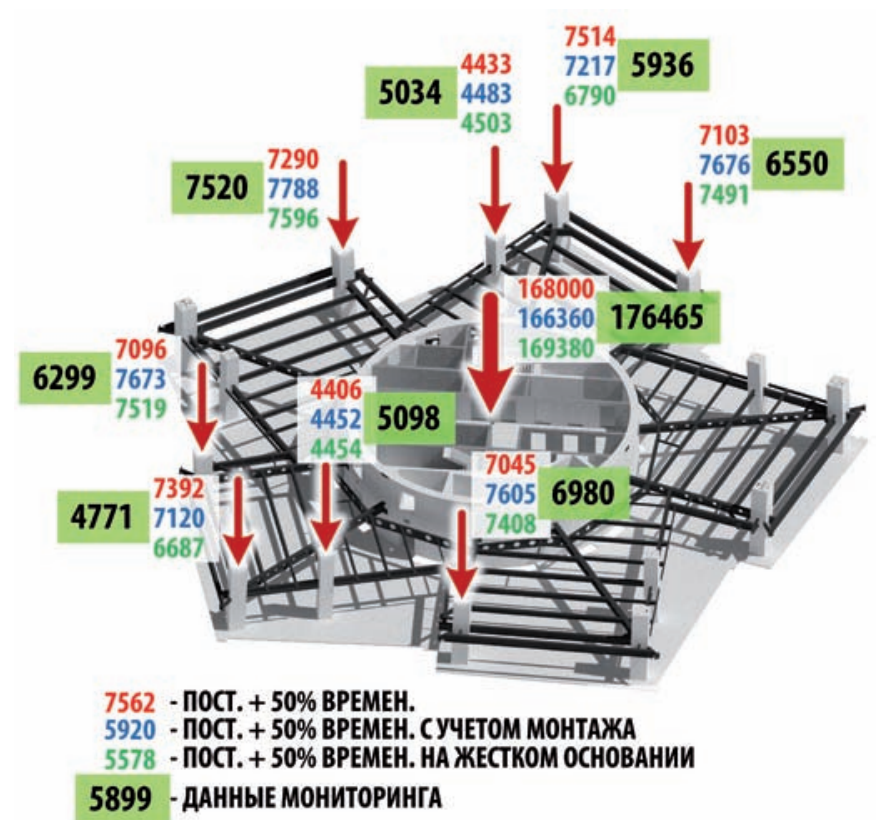

Puc. 26. Уровень L2. Нагрузки на конструкции, тс. Сравнение с результатами мониторинга
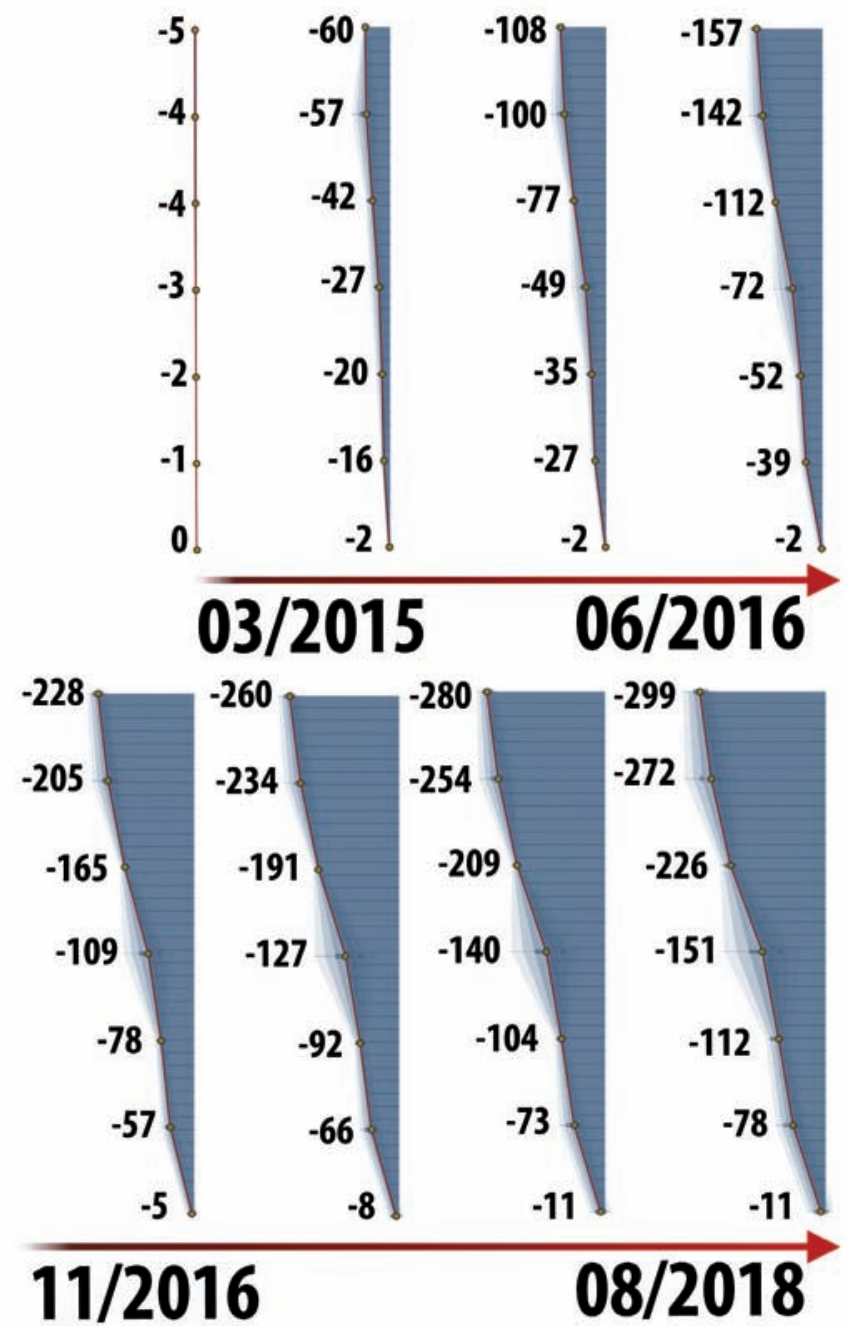

Рис. 27. Эпюра средней деформации ствола сваи №4, микрострейн
3) на те же самые нагрузки с учётом последовательности возведения и на абсолютно жёстком основании.

Результаты расчёта для уровня L2 приведены на рисунке 26. Суммарная расчётная нагрузка, приходящаяся на наблюдаемые конструкции в рассматриваемом уровне, отличается от измеренной менее чем на $2 \%$. Расхождение расчётных усилий, воспринимаемых отдельными композитными колоннами и ядром, с данными мониторинга находится в диапазоне 3-33\%.

Хорошее совпадение результатов мониторинга достигнуто и в уровне L5, где расчётная нагрузка, приходящаяся на ядро, отличается от измеряемой на 2,5\% К сожалению, неудовлетворительные результаты по нагрузке в ядре зафиксированы в уровне L8 (расхождение 46\%, возможные причины см. ниже).

B уровне L14 данные мониторинга указывают на существенную разницу в распределении нагрузки между колоннами и ядром по сравнению с результатами расчёта. Различие суммарной нагрузки на каркас составляет менее 7\%, однако на ядро, по данным мониторинга, приходится на $20 \%$ больше вертикального усилия, чем получено по данным расчётов. Предположительно, это объясняется включением в работу аутриггерных ферм, что подтверждается различием в наблюдаемых усилиях только в колоннах, расположенных под аутриггерами. Обработка всего объёма данных по деформации каркаса выше рассматриваемого уровня позволит более точно определить значения исследуемых параметров.

Серьёзным препятствием для расчёта напряжений и усилий в железобетонных конструкциях по показаниям датчиков деформации является необходимость принимать во внимание ползучесть материала, что учитывается при анализе данных с помощью понижения модуля деформации бетона.

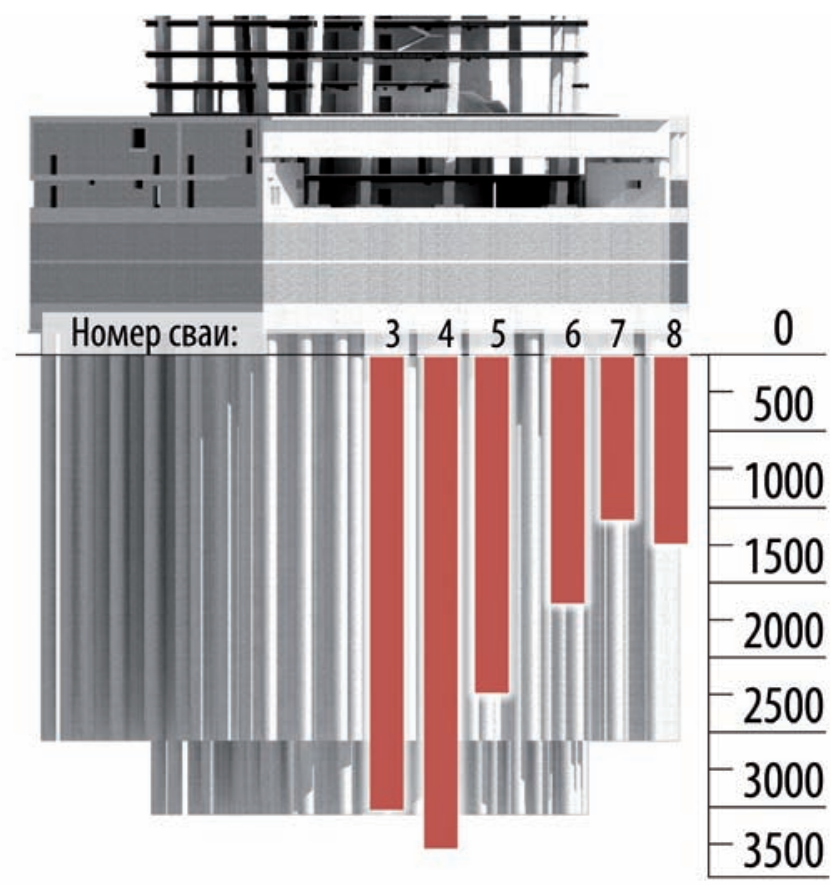

Рис. 28. Результаты мониторинга. Распределение усилий в головах свай в радиальном направлении на 01.08.2018, mс 
Для предварительной оценки влияния ползучести на результаты измерений можно воспользоваться соотношением между несущими способностями бетона и арматуры. Более точные данные можно получить по результатам натурных испытаний.

Учёт влияния ползучести на деформирование сталежелезобетонных колонн был проведён на основании результатов испытаний [6], которые показали, что стальной сердечник должен в среднем воспринимать около 60\% от общей нагрузки.

Анализ результатов мониторинга нижней плиты КФ показал, что деформация плиты в уровне двух нижних сеток армирования на значительной площади плиты находится в диапазоне 300-500 микрострейн, что превышает предельную допустимую для бетона деформацию растяжения при длительном действии нагрузки согласно [7] (270-360 микрострейн). Поэтому для расчёта усилий для нижней фундаментной плиты применялся пониженный модуль деформации бетона, соответствующий используемому в КЭ-модели.

Проектные решения по размещению датчиков деформации в композитных колоннах можно считать удачными - получены качественные данные, хорошо коррелирующие между собой и позволяющие произвести расчёт интегральных сжимающих усилий. Необходимо отметить, что в колоннах наиболее нагруженного наблюдаемого уровня L2 деформации гибкой арматуры составляют в среднем 92\%, а деформации бетона - 96\% от деформации сердечника, что подтверждает допустимость принятия гипотезы об их совместности. Стальные сердечники наблюдаемых колонн в этом уровне воспринимают 42-60\% от общей вертикальной нагрузки.

Для колонн уровня L14 соотношение между деформациями выглядит иначе: 76\% от деформации сердечника составляют деформации гибкой арматуры, 73\% - деформации бетона. Выводы о причинах повышенной деформативности сердечников, которые в этом уровне воспринимают 45-73\% общей нагрузки, будут сделаны после обработки данных мониторинга колонн по всем наблюдаемым уровням.

Результат мониторинга деформации стен ядра оказался менее очевидным. На некоторых из наблюдаемых этажей (в частности на уровне L8) выбор только пяти измерительных пунктов оказался достаточным для определения локальных напряжений в материале, но не позволяющим произвести точный расчёт нагрузки, воспринимаемой ядром. Анализ расчётного распределения напряжений в стенах ядра на таких этажах показал наличие большого количества концентраций, делающих поле напряжений весьма неоднородным. Поэтому осреднение по пяти точкам может приводить к существенной ошибке в расчёте усилия, воспринимаемого ядром.

В результате проведения мониторинга деформаций свайного поля были получены диаграммы деформирования стволов свай в процессе возведения Башни (рис. 27), на основании которых была рассчитана нагрузка, приходящаяся на голову каждой наблюдаемой сваи (рис. 28, расположение свай в плане см. на рис. 4).

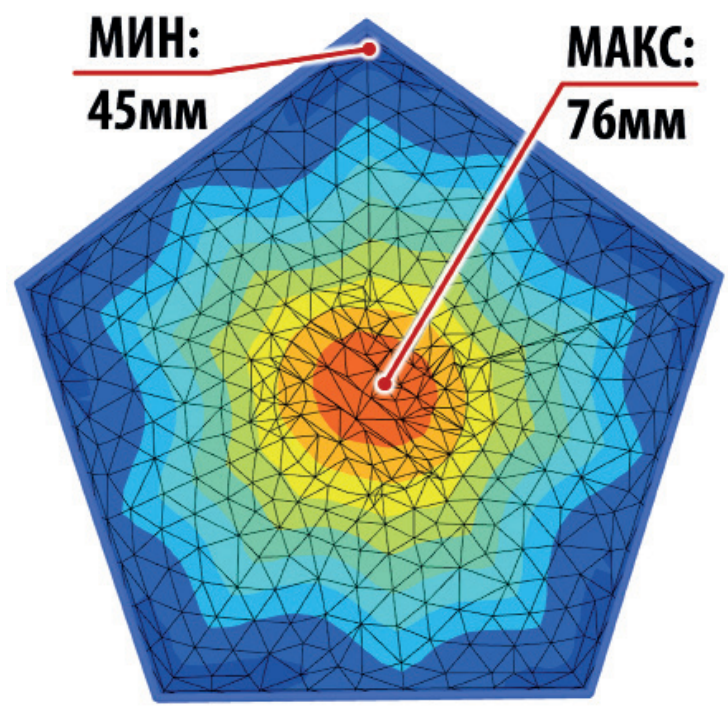

Рис. 29. Расчётная величина осадки фундамента на 01.08 .2018
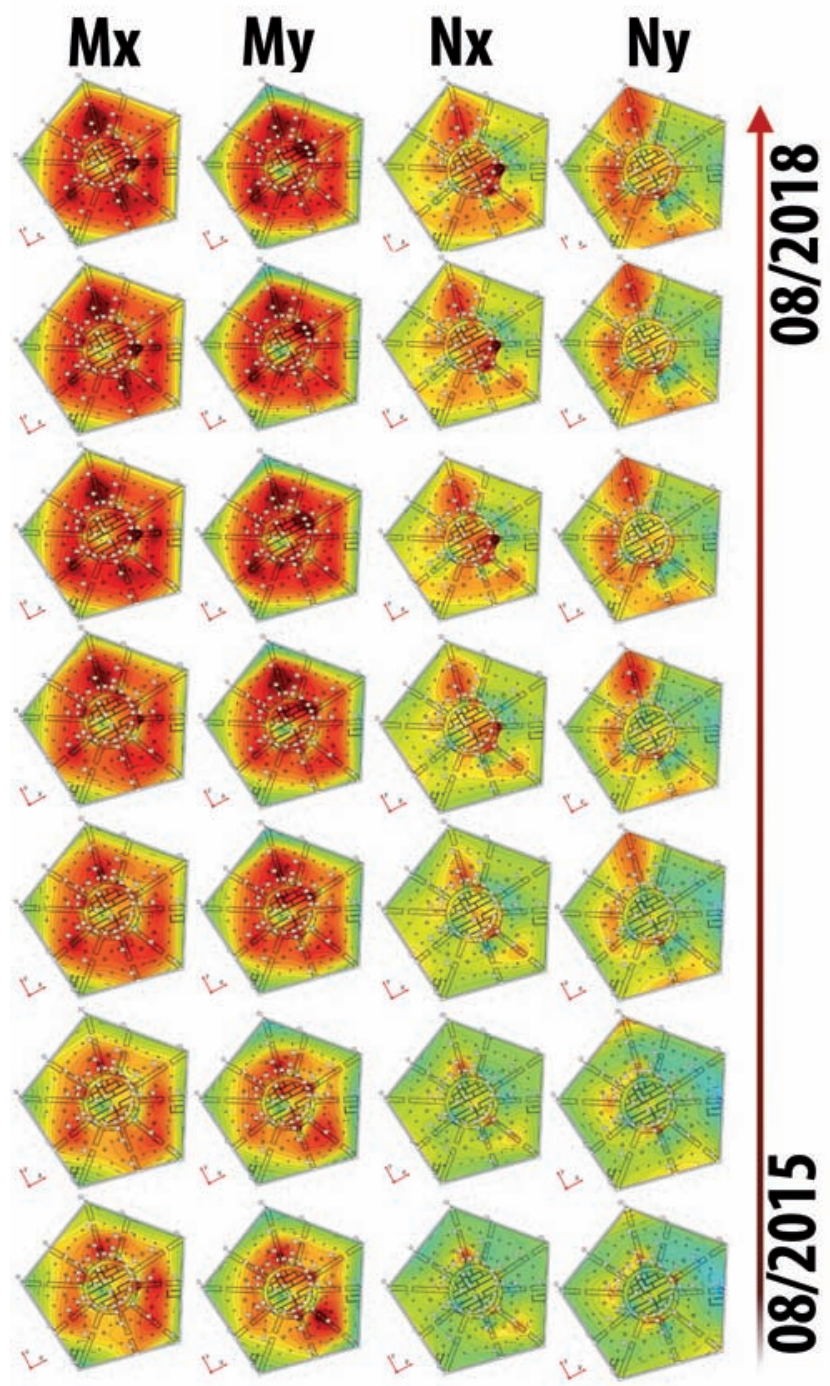

Рис. 30. Результаты мониторинга. Изополя внутренних усилий в нижней плите КФ 


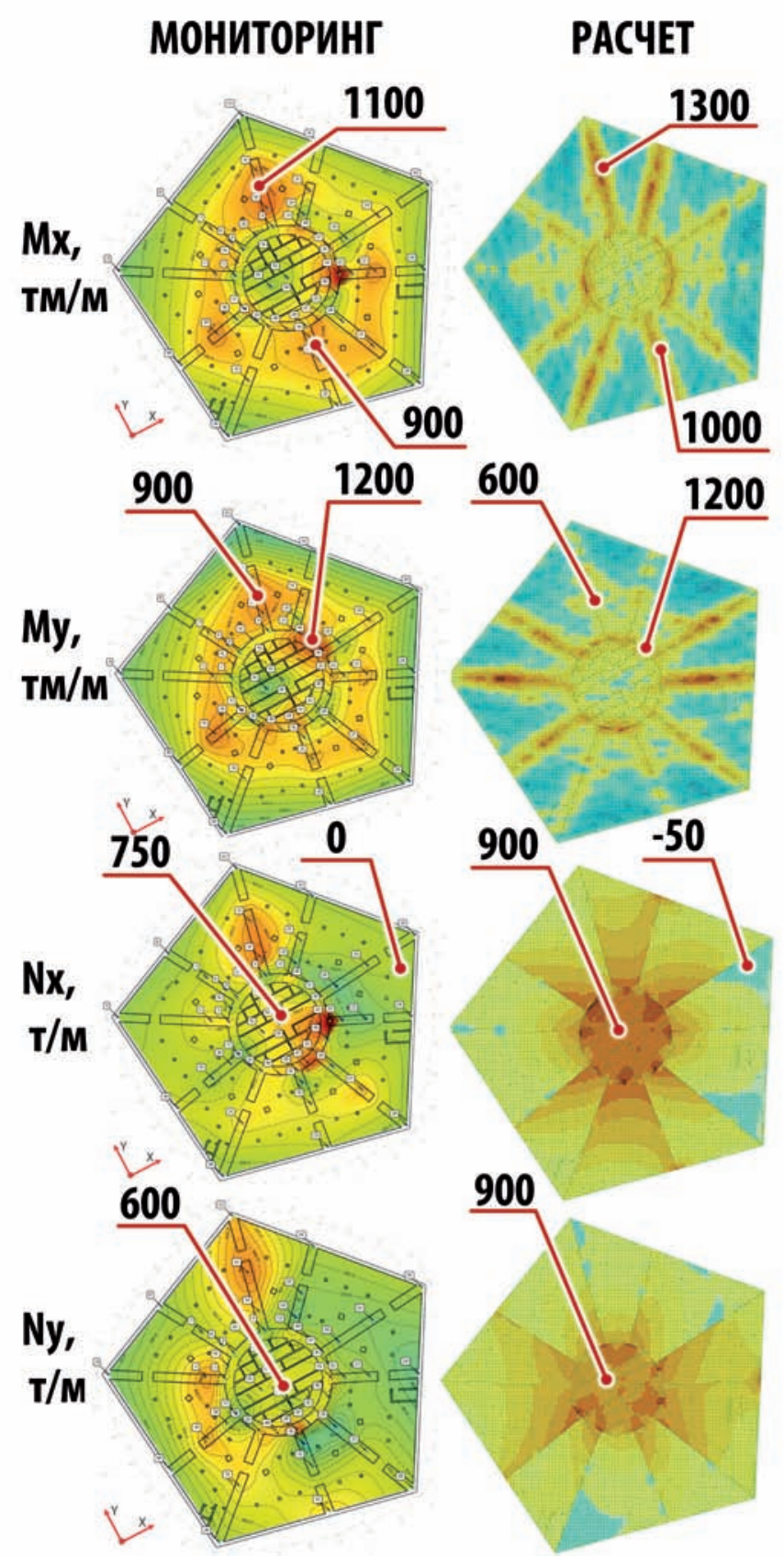

Рис. 31. Изополя внутренних усилий в нижней плите КФ. Сравнение с результатами расчёта

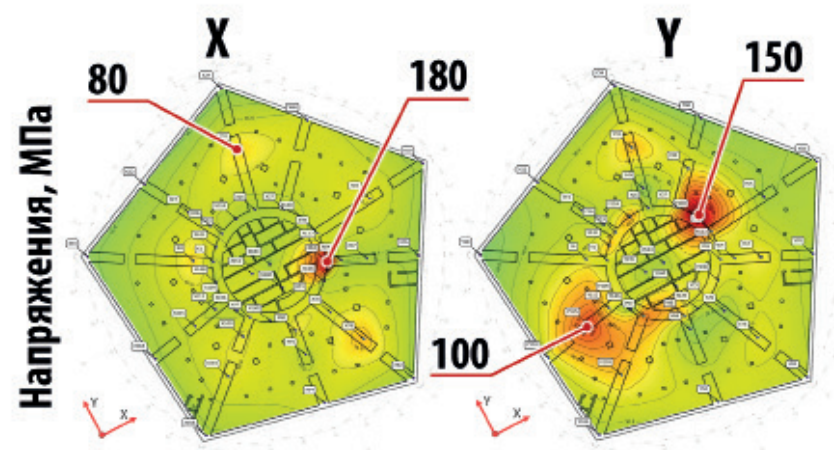

Рис. 32. Результаты мониторинга. Изополя напряжений в нижней арматурной сетке нижней плиты КФ
Анализ полученных данных показал, что наибольшую нагрузку (до 3460 тс) воспринимают сваи, расположенные в центральной части фундамента. Минимальная нагрузка при этом наблюдается на угловых сваях (924 тс). Отношение усилия в центральной свае к усилиям в крайних сваях находится в диапазоне 2,9-3,4, что не соответствует общим представлениям о работе свай в свайном поле. Такие результаты, возможно, являются следствием наличия более жёсткого основания. Данный вопрос требует проведения глубокого анализа результатов инженерно-геологических изысканий, испытания грунта сваями, анализа результатов измерений датчиков порового давления, послойных деформаций грунта и напряжений под подошвой ростверка, что будет рассмотрено в отдельной статье.

По данным периодически выполняемых геодезических измерений, средняя осадка фундамента Башни меньше расчётной, что может быть следствием отмеченной выше повышенной жёсткости основания или незавершённого процесса консолидации грунта (рис. 29).

По результатам измерения деформации в плитах КФ были определены напряжения и усилия в трёх наиболее нагруженных арматурных сетках нижней плиты и двух сетках верхней плиты, были рассчитаны напряжения в теле бетона. Путём интегрирования по высоте сечения эпюры нормальных напряжений были вычислены действующие в плитах изгибающие и мембранные усилия (рис. 30), которые сравнили с результатами конечно-элементного моделирования.

Результаты мониторинга нижней плиты КФ, приведённые на рисунке 31, показали, что расчётная жёсткость основания отличается от реальной (это косвенно подтверждается распределением нагрузки на сваи, показанным на рисунке 28), что приводит к различиям в характере распределения усилий по площади плиты. В то же время амплитудные значения усилий различаются от расчётных незначительно.

Проектные решения по мониторингу деформации нижней плиты КФ позволили определить реальные напряжения в рабочей арматуре, в частности, в наиболее нагруженной нижней арматурной сетке растягивающие напряжения не превышают 80 МПа (рис. 32), за исключением небольшого числа локальных концентраций.

В целом, система мониторинга охватывает весь комплекс основных несущих конструкций, обеспечивая возможность наблюдения за действительными значениями параметров НДС в процессе строительства и будущей эксплуатации. Несовпадения результатов расчёта с данными мониторинга в ряде случаев иллюстрируют необходимость в ходе проведения НТС вносить корректировки в расчётную модель по результатам обработки указанных данных.

Автоматизированная система мониторинга напряжённодеформированного состояния несущих конструкций Башни МФК «Лахта Центр» - пример успешного с инженерной точки зрения внедрения подобных систем, который позволил решить ряд задач по проведению научно-технического со- 
провождения строительства уникального объекта: уточнить нагрузки и деформационные характеристики материалов, установить реальную жёсткость основания, рассчитать действующие внутренние усилия в элементах конструкций и тем самым подтвердить надёжность и безопасность возведённого сооружения.

Обработка данных о деформации свайного основания, коробчатого фундамента, композитных колонн и центрального ядра выявила ряд неожиданных эффектов: раннее включение в работу аутриггерных ферм, более высокая загруженность центральных свай относительно краевых и др.

Сравнение результатов мониторинга деформаций с расчётами показало хорошее совпадение интегральных характеристик НДС большей части конструкций. Но при детальном рассмотрении для некоторых конструкций обнаружились существенные различия между ожидаемыми и наблюдаемыми напряжениями и усилиями, указывающие на недостаточную точность моделирования работы данных элементов под нагрузкой. При этом сложно представить, что подобные явления могут быть выявлены с помощью какого-либо другого источника информации, помимо системы мониторинга. Таким образом, для качественного решения задач НTC расчётная модель в процессе строительства должна постоянно уточняться и адаптироваться, а мониторинг в процессе адаптации должен являться обязательным мероприятием.

При этом система мониторинга не должна проектироваться номинально, как это часто бывает в практике оте-чественного строительства. Проект системы должен строго опираться на положения программы мониторинга, в которой в обязательном порядке должны быть определены контролируемые элементы конструкций, их параметры и сформулирована методология использования полученных значений контролируемых параметров для калибровки расчётных моделей основания, фундаментов и надземных частей сооружения.

Целесообразно проводить более интенсивную работу по разработке методологии калибровки КЭ-моделей сооружений на основании данных объективного инструментального контроля, предоставляемых автоматизированными системами мониторинга.

Внедрённая система является самой комплексной системой мониторинга в гражданском строительстве в нашей стране, сравнимой по своим масштабам с ведущими мировыми аналогами [8]. При этом, по нашим оценкам, общие затраты на систему не превысили 0,25\% от общей стоимости возведения МФК. СМДС, отдельные части которой эксплуатируются на протяжении более четырёх лет, показала отличную выживаемость и ремонтопригодность в тяжёлых и агрессивных построечных условиях.

В процессе строительства Башни накоплен огромный массив данных. Часть этой информации ещё только пред- стоит подвергнуть глубокому анализу компетентными специалистами. Наиболее интересные проблемы интерпретации результатов мониторинга и решения задач НTС с их помощью будут освещены в рамках отдельных статей.

Применение автоматизированных систем мониторинга значительно повысит надёжность уникальных зданий и увеличит безопасность долговременной эксплуатации.

Авторы выражают признательность всем организациям, участвующим в проекте, за помощь в реализации столь масштабной системы автоматизированного мониторинга.

\section{Лuтература}

1. Шулятьев, О.А. Основания и фундаменты высотных зданий / 0.А. Шулятьев. - Москва: АСВ, 2016. - 391 с.

2. Contreras, I.A. The Use of the Fully-Grouted Method for Piezometer Installation / I.A. Contreras, A.T. Grosser, R.H. VerStrate // Proceedings of the 7th International Symposium on Field Measurements in Geomechanics. - Boston, MA: FMGM, 2007.

3. McRae, J.B. Long-term stability of vibrating wire instruments. One manufacturer's perspective / J.B. McRae, T. Simmonds // Proceedings of the 3th International Symposium on Field Measurements in Geomechanics. - Oslo, Norway: FMGM, 1991. - C. 283-293.

4. DiBiagio, E.A. Case study of Vibrating-Wire Sensors That Have Vibrated Continuously For 27 Years / E.A DiBiagio // Proceedings of the 6th International Symposium on Field Measurements in Geomechanics. -0slo, Norway, 2003.

5. Sorum, G. Vibrating-wire reinforcement strain gauges for performance monitoring oflarge concrete structures / G. Sorum, T. Dyken // IABSE reports. - Norway, 1987.

6. Экспериментальные исследования сталежелезобетонных конструкций, работающих на внецентренное сжатие / В.И. Травуш, Д.В. Конин, Л.С. Рожко [и др.] //Academia. Архитектура и строительство. - 2016. - № 3. - С. 127-135.

7. СП 63.13330.2012. Бетонные и железобетонные конструкции. Основные положения / Введ. 2013-01-01. - М., 2013.

8. Abdelrazaq, A. Validating the Structural Behavior and Response of Burj Khalifa: Synopsis of the Full-Scale Structural Health Monitoring Programs / A. Abdelrazaq // International Journal of High-Rise Buildings. - 2012. - T. 1. - № 1.

\section{Literatura}

1. Shulyat'ev 0.A. Osnovaniya i fundamenty vysotnyh zdaniy / 0.A. Shulyat'ev. - Moskva: ASV, 2016. - 391 s.

6. Eksperimental'nye issledovaniya stalezhelezobetonnyh konstruktsiy, rabotayushhih na vnetsentrennoe szhatie / V.I. Travush, D.V. Konin, L.S. Rozhko [i dr.] //Academia. Arhitektura i stroitel'stvo. - 2016. - № 3. - S. 127-135.

7. SP 63.13330.2012. Betonnye i zhelezobetonnye konstruktsii. Osnovnye polozheniya / Vved. 2013-01-01. - M., 2013. 
Травуш Владимир Ильич, 1936 г.р. (Москва). Доктор технических наук, профессор, академик РААСН. Вице-президент Российской академии архитектуры и строительных наук (107031, Москва, Большая Дмитровка, 24, стр. 1. РААСН), главный конструктор ЗАО «Городской проектный институт жилых и общественных зданий». Сфера научных интересов: строительные конструкции, здания и сооружения; строительная механика; математическое моделирование, численные методы и комплексы программ. Автор более 300 научных трудов. Тел.: 8 (495) 650-77-83. E-mail: travush@raasn.ru.

Шахраманьян Андрей Михайлович, 1979 г.р. (Москва). Кандидат технических наук. Генеральный директор 000 «СодИС ЛАБ» (117556, г. Москва, Болотниковская, 11, корпус 1. СОДИС-ЛАБ). Сфера научных интересов: автоматизированные системы мониторинга зданий и сооружений, технологии информационного моделирования (ВIM) зданий. Автор более 50 публикаций, патентов и нормативных документов. Тел.: 8 (495) 545-48-40. E-mail: info@sodislab.com.

Колотовичев Юрий Александрович, 1985 г.р. (Москва). Кандидат технических наук. Доцент кафедры «Строительная и теоретическая механика» ФГБУ В0 «НИУ МГСУ» (129337, г. Москва, Ярославское шоссе, д. 26. МГСУ), заместитель директора 000 «СОДИС ЛАБ» по научной работе (117556, г. Москва, Болотниковская, 11, корпус 1). Сфера научных интересов: системы мониторинга технического состояния зданий и сооружений, строительная механика, математическое моделирование, динамика сооружений. Автор более 15 публикаций. Тел.: +7 (495) 545-48-40. E-mail: ykol@sodislab.com.

Шахворостов Алексей Иванович, 1976 г.р. (Москва). Кандидат технических наук. Управляющий партнёр «ИНФОРСПРОЕКТ» (115280, г. Москва, ул. Ленинская слобода, д. 19. ИНФОРСПРОЕКТ). Сфера научных интересов: строительные конструкции, здания и сооружения. Автор проектов 11 построенных уникальных объектов. Автор более 30 научных и технических публикаций, докладов на профильных конференциях Тел.: 8 (495) 269-19-59. E-mail: a.shakhvorostov@inforceproject.ru.

Десяткин Михаил Александрович, 1981 г.р. (Москва). Главный специалист «ИНФОРСПРОЕКТ» (115280, г. Москва, ул. Ленинская слобода, д. 19). Сфера научных интересов: строительные конструкции, здания и сооружения; строительная механика; математическое моделирование, численные методы и комплексы программ. Автор научных и технических публикаций, докладов на профильных конференциях. Автор проектов уникальных объектов. Тел.: 8 (495) 269-19-59 E-mail: m.desyatkin@inforceproject.ru

Шулятьев Олег Александрович, 1956 г.р. (Москва). Кандидат технических наук. Заместитель директора Научно-исследовательского, проектно-изыскательского и конструкторско-технологического института оснований и подземных сооружений им. Н.М. Герсеванова А0 «НИЦ «Строительство» (109428, г. Москва, 2-я Институтская ул., д.6, корпус 1. НИИОСП им. Герсеванова). Автор более 100 научных трудов, из них 3 монографии и 42 изобретения. Сфера научных интересов: расчёт и проектирование фундаментов высотных зданий, защита существующих зданий при подземном строительстве в условиях плотной городской застройки. Тел.: 8 (499) 170-57-83. E-mail: niiosp35@yandex.ru.

Шулятьев Станислав Олегович, 1985 г.р. (Москва). Кандидат технических наук. Старший научный сотрудник Научно-исследовательского, проектно-изыскательского и конструкторско-технологического института оснований и подземных сооружений им. Н.М. Герсеванова АО «НИЦ «Строительство» (109428, г. Москва, 2-я Институтская ул., д.6, корпус 1. НИИОСП им. Герсеванова). Сфера научных интересов: системы мониторинга технического состояния зданий и сооружений, расчёты системы «основание-фундамент-сооружение», расчёт и проектирование фундаментов высотных зданий. Автор более 25 работ. Тел.: 8 (499) 170-27-26. E-mail: shulyatevs@yandex.ru.

Travush Vladimir Ilyich, born in 1936 (Moscow). Doctor of Technical Sciences, Professor, Academician of RAACS. Vice-President in the field of Construction Sciences of the Russian Academy of Architecture and Construction Sciences (24 Bolshaya Dmitrovka, build. 1, Moscow, 107031. RAACS), Chief Structural Engineer of ZA0 "City Design Institute for Residential and Public Buildings". The author of more than 300 publications. Scientific interests: building structures, buildings and structures; structural mechanics; mathematical modeling, numerical methods and program complexes. Tel.: +7 (495) 650-77-83. E-mail: travush@raasn.ru.

Shahramanyan Andrey Mikhailovich, born in 1979 (Moscow). Candidate of Technical Sciences. CEO at SODIS LAB, Moscow. Academic Interest: structural health monitoring, building information modelling. The author of more than 50 publications, patents and regulations in the field of structural health monitoring. Tel.: +7(495) 545-48-40. E-mail: info@sodislab.com

Kolotovichev Yury Aleksandrovich, born in 1985 (Moscow). Candidate of Technical Sciences. Senior R\&D engineer at S0DIS LAB, Moscow, Russia. Assistant Lecturer at the Department of Structural Mechanics of Moscow State University of Civil Engineering. 
Teaching structural mechanics basics in higher-school. Academic interest: structural health monitoring, structural mechanics, in-situ instrumentation and survey, solid mechanics, digital signal analysis, structural Vibration Measurement and Analysis. The author of more than 15 publications. Tel.: +7 (495) 545-48-40. E-mail: ykol@sodislab.com

Desyatkin Mikhail Aleksandrovich, born in 1981 (Moscow). Senior structural engineer/Principal at INFORCEPROJECT, Moscow. Studied structural engineering at Moscow State University of Civil Engineering (graduated in 2003), the author of research publications in the field of structural engineering and completed projects of unique venues and buildings, awarded structural engineer. Tel.: +7 (495) 269-19-59 E-mail: m.desyatkin@inforceproject.ru.

Shulyatyev Oleg Aleksandrovich, born in 1956 (Moscow). Candidate of Technical Sciences. Deputy director at the JSC "NIC "Stroitelstvo" - NIIOSP named after N.M. Gersevanov. The winner of State Prize of the Russian Federation in the field of science and technology for 2013 award, honorary builder of Moscow and Russia. Scientific interests: skyscraper design, protection of existing buildings in underground construction in dense urban areas. The author of more than 100 publications, 3 monographs and 42 inventions. Tel.: +7 (499) 170-57-83. E-mail: niiosp35@yandex.ru

Shulyatyev Stanislav Olegovich, born in 1985 (Moscow). Candidate of Technical Sciences. Senior staff scientist at the JSC "NIC "Stroitelstvo" - NIIOSP named after N.M. Gersevanov. Scientific interests: monitoring systems, soil-structure interaction calculations, skyscraper design. The author of more than 25 publications. Tel.: +7 (499) 170-27-26. E-mail: shulyatevs@yandex.ru 